
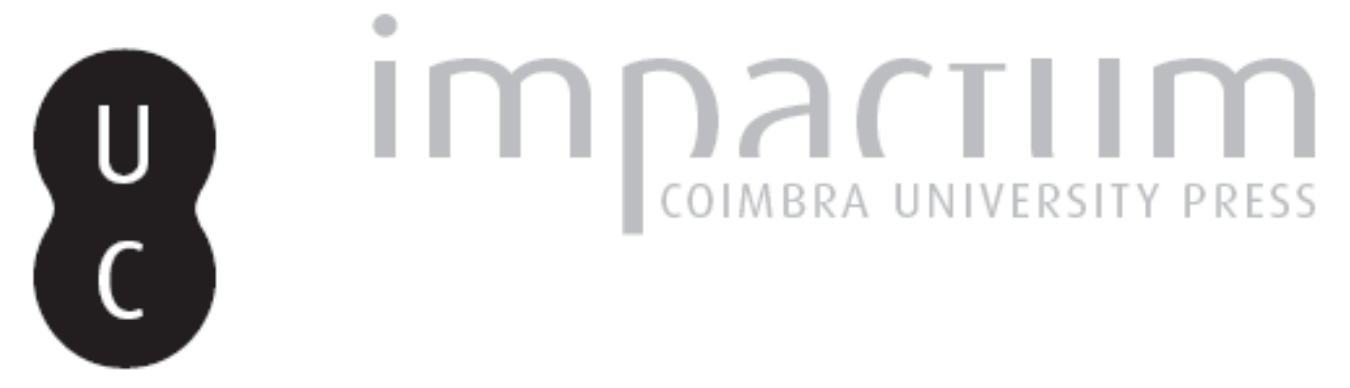

La Midienne à la lumière du code rhétorique présent dans la Rhétorique à Alexandre

Autor(es): $\quad$ Fernandes, Marcelo Vieira

Publicado por: Sociedade Brasileira de Estudos Clássicos

URL persistente:

URI:http://hdl.handle.net/10316.2/35789

DOI:

DOI:http://dx.doi.org/10.14195/2176-6436_23_4

Accessed : $\quad$ 26-Apr-2023 12:31:21

A navegação consulta e descarregamento dos títulos inseridos nas Bibliotecas Digitais UC Digitalis, UC Pombalina e UC Impactum, pressupõem a aceitação plena e sem reservas dos Termos e Condições de Uso destas Bibliotecas Digitais, disponíveis em https://digitalis.uc.pt/pt-pt/termos.

Conforme exposto nos referidos Termos e Condições de Uso, o descarregamento de títulos de acesso restrito requer uma licença válida de autorização devendo o utilizador aceder ao(s) documento(s) a partir de um endereço de IP da instituição detentora da supramencionada licença.

Ao utilizador é apenas permitido o descarregamento para uso pessoal, pelo que o emprego do(s) título(s) descarregado(s) para outro fim, designadamente comercial, carece de autorização do respetivo autor ou editor da obra.

Na medida em que todas as obras da UC Digitalis se encontram protegidas pelo Código do Direito de Autor e Direitos Conexos e demais legislação aplicável, toda a cópia, parcial ou total, deste documento, nos casos em que é legalmente admitida, deverá conter ou fazer-se acompanhar por este aviso.

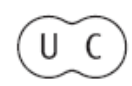




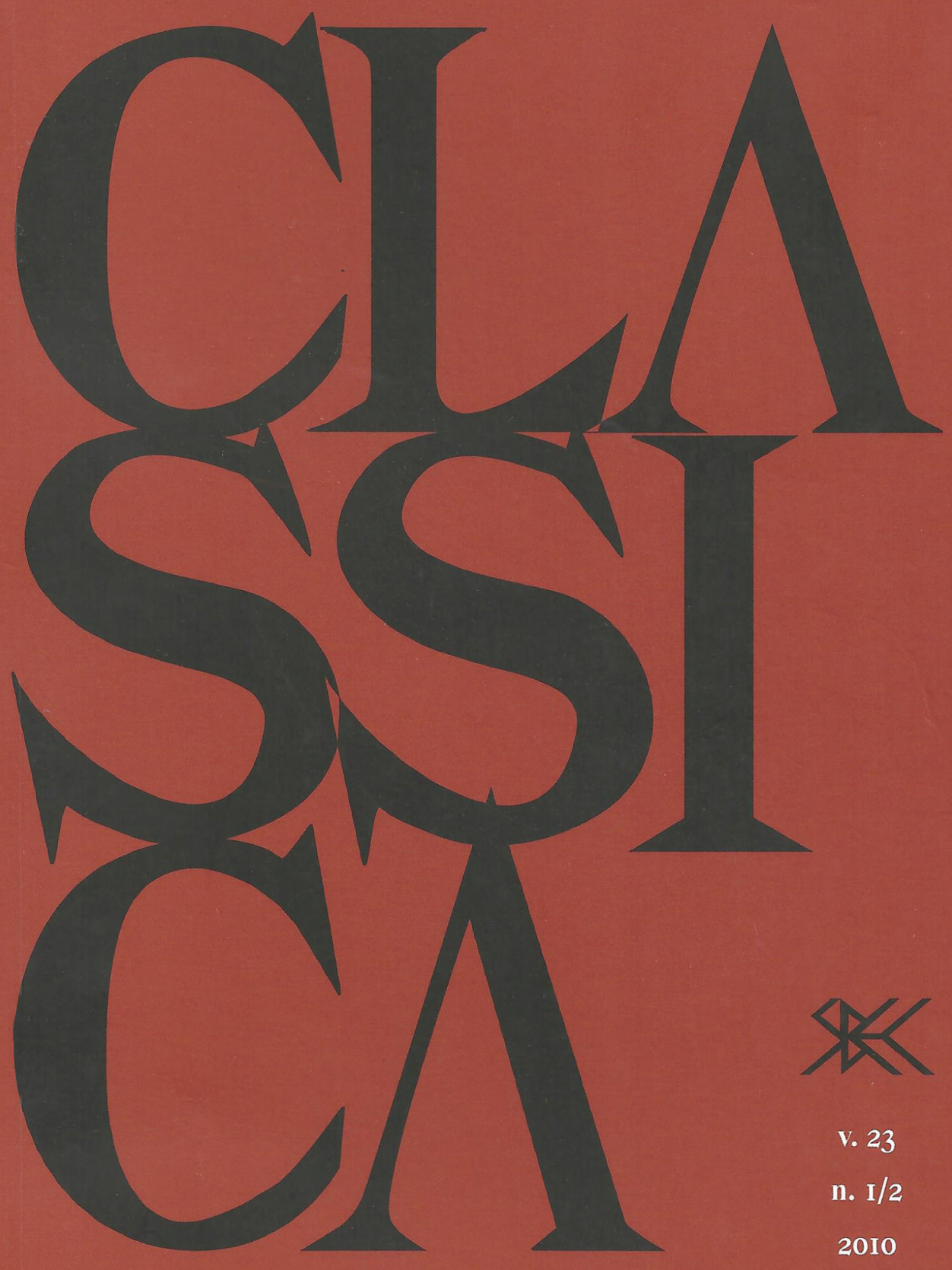




\title{
La Midienne à la lumière du code rhétorique présent dans la Rhétorique à Alexandre
}

\author{
Marcelo Vieira Fernandes \\ Universidade de São Paulo \\ Brasil
}

RÉsumÉ. La Rhétorique à Alexandre (Rh. Al.), normalement atribuée au sophiste Anaximène de Lampsaque (c. 380-320 av. J.-C.), peut être une voie pour la connaissance de ce qui se trouvait dans les manuels de rhétorique en usage dans la première moitié du IV ${ }^{\mathrm{e}}$ siècle av. J.-C. et, à partir de là, pour une connaissance plus précise du code rhétorique pratiqué par les orateurs attiques. L'objectif de cette étude est de démontrer que le code rhétorique présent dans la $R h$. $A l$., où il se trouve en l'état de préceptes, apparaît également en l'état de discours, c'est-à-dire en l'état de pratique, dans le cas de la Midienne de Démosthène.

Mots-ClÉs. Rhétorique à Alexandre; Midienne; Démosthène; rhétorique ancienne; pratique oratoire.

La publication de l'édition critique de la Rhétorique à Alexandre (Rh. Al.), du Ps.-Aristote, dans la Collection des Universités de France ${ }^{1}$, en traduction française de $\mathrm{P}$. Chiron, nous permet de dire que n'existe plus la raison prosaïque - l'accessibilité du texte limitée au seul texte grec (ou dans ses traductions anglaise, allemande et espagnole) - que ce dernier signale $^{2}$, pour sa quasi ${ }^{3}$ non-utilisation, par exemple, dans le commentaire

Email: marcelovfernandes@yahoo.com.br

Cet article est la version modifiée et adaptée de la monographie que j’ai présentée comme travail de conclusion du séminaire Rhétorique Ancienne, assuré par le Prof. Pierre Chiron à l’Université de São Paulo en 2003.

${ }^{1}$ Ps.-Aristote, Rhétorique à Alexandre, t. établi et traduit par Pierre Chiron, Paris, C. U.F., 2002. C'est à cette édition (et traduction) que nous nous reporterons pour les citations de la $R h$. Al. dans ce texte.

${ }^{2}$ Cf. P. Chiron, La Rhétorique à Alexandre et les orateurs attiques (version dévelopée d'une communication présentée au XI ${ }^{\mathrm{e}}$ congrès de l'International Society for the History of Rhetoric, Saskatoon, juillet 1997), Letras Clássicas 4, 2000, p. 111.

${ }^{3}$ A l'exception de publications plus récentes, nous reprenons ici celles qui sont citées par $\mathrm{P}$. Chiron (ib., n. 4): P. Moraux, Thucydide et la rhétorique, Les Études Classiques 22, 3-23, 1954 ; F. Romero Cruz, Tucídides VI 16 y la retórica a Alejandro, Stephanion (Salamanca), 149-53, 1988. Rappelons également la grande édition de Leonardus Spengel (Anaximenis 
des orateurs attiques. Pour ce qui est des autres raisons, plus contraignantes - les doutes au sujet de son attribution ${ }^{4}$ et le degré de fiabilité du texte partiellement retouché - elles incitent plutôt à la prudence qu'à un simple refus de son usage : en effet, si l'on prend en compte sa datation (entre 340 et 300), ainsi que son orientation sophistique (dans une tradition revue par Isocrate), la $R h . A l$. peut être une voie pour la connaissance de l'essentiel de ce qui se trouvait dans les manuels de rhétorique en usage dans la première moitié du IVe siècle, et, à partir de là, pour une connaissance plus précise du code rhétorique pratiqué par les orateurs attiques ; de surcroît, malgré quelque ressemblance entre son mode de présentation et celui d'Aristote dans la Rhétorique, la $R h$. Al. peut également aider à éclairer le contexte des doctrines rhétoriques pré-aristotéliciennes ${ }^{5}$.

Mais ne répétons pas les arguments qui justifient l'adoption de la $R h$. Al. - source privilégiée si on la compare aux documents conservés de la même époque - pour la compréhension et l'exégèse de l'éloquence grecque : il suffit pour cela de renvoyer le lecteur à l'article évoqué de $\mathrm{P}$. Chiron, ainsi qu'à l'introduction de son édition critique. Ce que nous proposons dans ce travail, à partir de telles justificatives, c'est l'utilisation de la $R h$. Al. dans l'exégèse, encore que partielle, d'un discours de Démosthène, le C. Midias. Nous avons ainsi cherché, moyennant un examen d'un seul discours, à vérifier l'applicabilité du code rhétorique présent dans la $R h$. $A l$. à la lecture et l'interprétation d'un orateur dont la production a lieu à la même époque que la composition du traité.

\section{La méthode}

C'est pour considérer que la $R h$. Al., de par sa richesse même, est le résultat de plus d'un siècle d'influences (Protagoras, Gorgias, Isocrate, entre autres) que nous disons 'le code présent dans la $R h$. $A l$ '. Ceci dit, nous recourrons au texte sans particulariser de telles influences, même lorsqu'elles apparaissent indiscutables, car il ne s'agit pas ici de vérifier le lien entre

Ars Rhetorica quae uulgo fertur Aristotelis ad Alexandrum, Turici et Vitoduri, 1844 [Leipzig, 1850 ; Hildesheim, 1981]), dans laquelle, avec les commentaires, il est fait de nombreuses références au corpus des orateurs attiques; et évidemment, l'édition de P. Chiron, à laquelle nous nous reportons, dans laquelle ces références sont encore plus nombreuses. ${ }^{4}$ On donne souvent le texte comme étant du sophiste Anaximène de Lampsaque (c. 380-320). ${ }^{5}$ Quant à son usage, toutefois, dans l'interprétation de la classification des trois genres, cf. L. Pernot: 'Force est de la (sc. la $R h$. Al.) tenir en marge de l'enquête, malgré qu'on en ait, parce qu'elle autorise des conclusions contradictoires suivant la manière dont on l'interprète et éventuellement dont on la corrige' (L. PERnOT, Aristote et ses devanciers. Pour une archéologie du discours délibératif, Letras Clássicas 4, 2000, p. 73). 
un procédé quelconque chez Démosthène et un précepte spécifique à l'intérieur de cette tradition d'influences; il s'agit bien plutôt d'esquisser une lecture d'un discours de Démosthène à la lumière d'un document technique qui témoigne, presque de manière impersonnelle, de la pratique oratoire à l'époque même de Démosthène. Pour la confrontation entre le code et les faits pointés dans le discours, nous chercherons - sans nous contenter de marquer les ressemblances terminologiques - à suivre les paramètres d'exégèse recommandés par P. Chiron dans l'article mentionné ${ }^{6}$, en classifiant et interprétant de tels faits - dont le nombre cherchera, pour chaque cas, à être exhaustif - à partir de la notion que le code rhétorique intervient comme médiat entre les divers termes de la relation rhétorique, à savoir : l'orateur, le public, et le procès (les trois termes de la relation aristotélicienne), auxquels s'ajoute, dans le genre judiciaire tout particulièrement, l'adversaire. Ainsi dans le cas spécifique du C. Midias, nous observerons, en ce qui concerne le code, (1) son 'application' ((a) dans la 'modification de la perspective', (b) dans la 'défloration' et (c) dans 'l'exploitation des inductions spontanées') ; et (2) sa 'surdétermination' et son 'retournement'.

\section{La Midienne}

Si l'on se fie à ce que Démosthène lui-même nous dit', l'antagonisme entre lui et Midias commence dès $363^{8}$, quand celui-ci, sous la menace

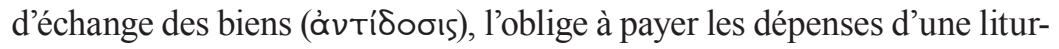
gie, le menant au bord de la ruine ; Démosthène le poursuit pour injures

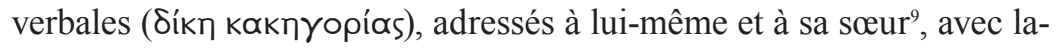
quelle il vivait ; mais Midias, non seulement ne comparaît pas, mais de plus parvient à faire subir à Straton, arbitre responsable du cas, l'exclusion et l'indignité civique (å tı $\left.\mu_{i ́ \alpha}\right)^{10}$; dès lors l'inimitié entre eux croît - en raison surtout de l'opposition que fait Démosthène au groupe d'Eubule, qui bénéficiait de l'appui de Midias - à tel point qu'en 348 Démosthène envisage

\section{${ }^{6}$ Cf. p. $112-16$.}

${ }^{7}$ Et c'est là, en principe, une limitation supplémentaire à une analyse 'pragmatique' de son discours. Cf. infra.

${ }^{8}$ Cf. C. Midias, $77-81$.

${ }^{9}$ Cf. ib., 79 : '(...) devant ma soeur ils (sc. Midias et son frère) qui vivait encore chez nous - une petite fille à l'époque - ils dirent toutes les horreurs qu'on peut attendre de pareils gens - non ! on ne me fera pas répéter ce qu'ils on dit alors ! - et déversèrent sur ma soeur, sur moi, sur nous tous des ignominies qu'on peut et qu'on ne peut pas dire' (trad. de Jean Humbert, Paris, "Les Belles Lettres", 1959, de même que celle de toutes les citations du C. Midias et celle du Contre Ctésiphon, de la note 19, faites dans ce travail).

${ }^{10}$ Cf. ib., 82-88. 
de présenter une nouvelle action contre lui (pour Démosthène, de caractère public) : le fait est, qu'à l'occasion des Grandes Dionysies de cette date, la tribu Pandionis, qui était celle de Démosthène, n'ayant pas désigné de chorège ne pourrait pas présenter sa contribution aux chœurs ; Démosthène assume alors les charges de la chorégie, s'attirant tous les éloges : Midias, quant à lui, après diverses tentatives de sabotage ${ }^{11}$ (dont celle de détruire les vêtements et les ornements d'or commandés par Démosthène), ne se contenant plus, agresse Démosthène ${ }^{12}$, devant un public composé non seulement d'Athéniens, mais aussi d'étrangers ${ }^{13}$; Démosthène recourt donc au procédé de la троßо $\lambda$ ń, la "plainte préalable", obtenant contre Midias,

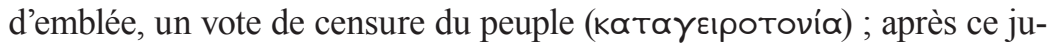
gement, de caractère seulement moral, le prochain pas serait de présenter l'affaire devant un tribunal, qui devrait se prononcer sur le discours (ou la Tínпoı) de l'une ou de l'autre des parties.

De son côté, Démosthène soutient que l'insulte dont il a été victime n'a pas seulement visé sa personne, mais a également constitué un outrage public, puisque, l'atteignant dans l'exercice de ses fonctions de chorège, elle atteint également les lois, le Dieu dont il s'est constitué chorège et même la Religion ${ }^{14}$; par contre, en ce qui concerne Midias... l'orateur Démosthène nous avance quel sera à ce sujet l'argument de son adversaire : si Démosthène a subi réellement ce qu'il dit avoir subi, il ne devrait alors

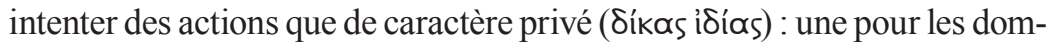
mages matériels, une autre pour l'outrage souffert au préjudice de sa seule

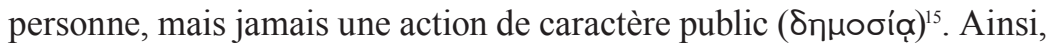
le status quaestionis du discours, anticipé de la sorte par Démosthène ${ }^{16}$, est ce qui a trait à la définition du conflit en tant que privé ou que public ${ }^{17}$.

\footnotetext{
${ }^{11}$ Cf. ib., 16-17.

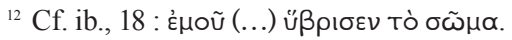

${ }^{13}$ Cf. ib., $74 ; 217$.

${ }^{14}$ Cf., p. ex., ib., 126-127.

${ }^{15}$ Cf. ib., 25.

${ }^{16} \mathrm{Cf}$. ib., 28 : '(...) qu'il montre qu'il n'a pas fait ce dont je l'accuse ou, s'il a fait, que ce fut sans offense à la fête. Voilà pourquoi je lui ai intenté une plainte préalable, et c'est la ques-

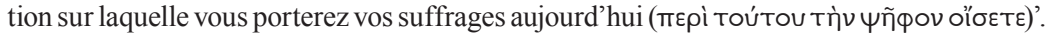
${ }^{17}$ C'est ainsi que l'interprète l'auteur du second argument présent dans l'édition de J.

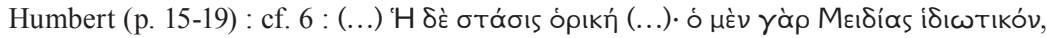

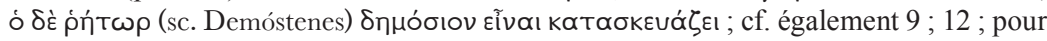
l'auteur du premier argument (ib., p. 14-15), il s'agit du même status, mais l'opposition est

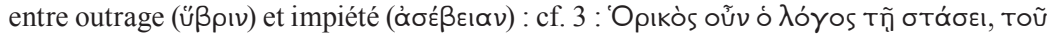

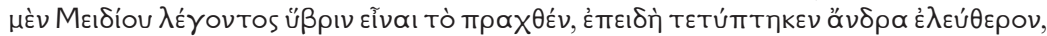

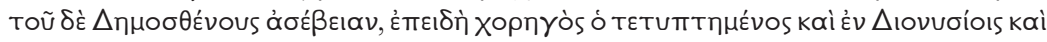


Cependant, malgré la série de vilenies dont Démosthène dit avoir été la victime, et bien qu'il déclare dès l'exorde ${ }^{18}$ de la Midienne qu'il ne saurait y avoir ni pot-de-vin ni menaces qui le fassent renoncer à son procès contre Midias, il faut bien constater que ce discours ne fut pas prononcé (ce qui, d'ailleurs, lui valu plus tard (en 330) d'être accusé d'avoir vendu sa cause ${ }^{19}$ ). Il faut ajouter à ceci que c'est de la seule bouche de Démosthène ${ }^{20}$ que nous sommes informés de ces faits et que, la Tínnoıs de Démosthène n'ayant pas été proposée effectivement, il n'y a pas eu de discours de la part de Midias.

On voit donc clairement les limites d'une recherche qui vise à prendre en compte les données concrètes de la communication rhétorique, selon un point de vue 'pragmatique ${ }^{21}$. Ceci, sans mentionner que, même pour les discours prononcés, une telle recherche ne va pas de soi, en raison de la difficulté qu'il y a d'établir les faits extra-textuels. La différence, c'est que, dans le cas particulier de l'examen du C. Midias, la formation rhétorique de Démosthène est information qui n'est pas négligeable : (1) d'une part, il est certain que l'on peut dire que l'orateur fait preuve de sa maîtrise du code rhétorique ; (2) d'autre part, qu'il manifeste, dans son texte, la conscience que cette maîtrise peut être perçue par le public ; on peut affirmer également que, dans le traitement du procédé, il laisse transparaître - quand, par exemple, il présente un même fait tantôt d'une manière amplifiée, tantôt de mode simple - l'usage qu'il fait de ce code, et enfin, qu'il cherche à épingler, chez l'adversaire, la possibilité d'un usage perverti de ce même code.

C'est ce que nous chercherons à démontrer par la suite.

\section{Analyse}

Étant donné que, du point de vue du code rhétorique, Démosthène n'affirme aucune incapacité ni ingénuité à l'utiliser, l'analyse portera ici

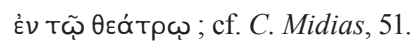

${ }^{18} \mathrm{Cf}$. ib., 3 : ‘(...) j'aurais pu toucher la forte somme à condition de me désister, mais je n'ai rien touché ; j'ai subi en quantité des sollicitations, des avances... et aussi, par Zeus, des menaces'.

${ }^{19} \mathrm{Cf}$. Eschine, Contre Ctésiphon, 52 : '(...) il a vendu pour trente mines à la fois l'outrage qu'il avait subi et le vote de censure prononcé par le peuple contre Midias'. En fait, il s'agira d'éviter une rupture avec le parti d'Eubule (auquel appartenait Midias) et d'empêcher ainsi que les divisions internes affaiblissent la position d'Athènes face à Philippe.

${ }^{20}$ Cf., p. ex., C. Midias, 126 : 'Tous les outrages qui m'ont atteint dans ma charge et dans ma personne, toutes les sortes d'attentats et de mauvais traitements auxquels j'ai fini par échapper, vous les conaissez maintenant de ma bouche, Athéniens'.

${ }^{21}$ Cf., à ce sujet, l'article cité de P. Chiron, p. 116. 
- nous l'avons dit - sur (1) l'application de ce code, et (2) sur sa surdétermination (et à partir de celle-ci, sur le retournement du code, sous la forme que nous croyons pouvoir le distinguer dans le texte).

\subsection{Application du code}

Dans le cas particulier du C. Midias, l'application du code semble se produire particulièrement en trois points : (1) dans la modification de perspective; (2) dans la réfutation anticipée (procatalepse) des arguments de l'adversaire - la défloration ; et (3) dans l'exploitation des inductions spontanées.

\subsubsection{Modification de la perspective}

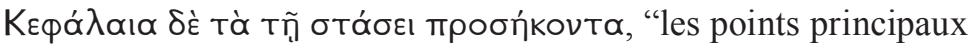
(sc. du discours) sont en rapport avec la position adoptée", dit l'auteur du second argument ${ }^{22}$. Autrement dit, la perspective dans laquelle l'orateur présente son argumentation découle déjà du status même de la question. Nous savons que la position de Démosthène est que sa cause a une dimension non seulement particulière, mais publique. De là, la stratégie de l'orateur est de faire de l'outrage reçu par sa personne, un outrage qui atteint la cité entière, dans la mesure où, l'ayant atteint en tant que chorège, il porte aussi atteinte aux Lois et à la Religion. Pour mettre cette stratégie en pratique, l'instrument adopté est sans aucun doute l'amplification, comme le rappelle l'auteur de ce même argument :

(...) l'exorde est très violent, grossissant beaucoup les circonstances

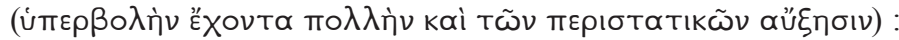
les expressions 'à l'égard de tous, non seulement à mon égard' (Tò трòs ăтா dénoncent chez Midias une sorte d'entraînement à la violence, et ne s'appliquent pas à un seul égarement fortuit (8).

Cette amplification, à son tour, procède surtout par le grossissement - dans quatre directions principales (cf. infra: 3.1.1.1) - du caractère criminel des actions de Midias. Or, l'amplification de ce qui est vil, dans la circonstance de la censure, peut être entendu comme amplification d'actions viles, par ce que l'on peut lire de la comparaison faite par le rhéteur entre les espèces de l'éloge et de la censure : 
En bref, l'espèce de l'éloge est l'amplification ( $\propto u ̛ \xi \eta \sigma ı)$ d'options,

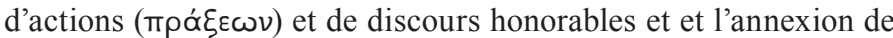
tels biens s'ils n'existent pas. L'espèce du blâme est le contraire, le rebaissement de ce qui est honorable et l'amplification de ce qui est vil (Rh. Al., 3, 1425 b 36-39).

Enfin, l'amplification, comme nous avons cherché à en donner un exemple, peut se réaliser au moyen des opérations de contraste, de compétition et d'omission 'pleine' (sous les formes de la prétérition et du sous-entendu) (cf. infra).

\subsubsection{Effet de masse}

Parmi les effets de masse, nous n'examinerons pas ici les moyens de l'amplification stylistique, mais seulement ceux qui ont trait au contenu. Ces derniers, nous les répartissons - ainsi que nous l'avons dit - en quatre directions principales : l'orateur réitère, de différentes manières, que (a) son adversaire lui a fourni une matière abondante pour l'accusation (cf., p.

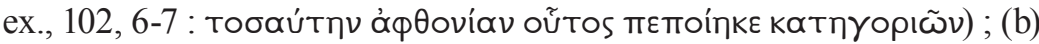
que l'outrage qu'il a subi est intentionnel, qu'il y a donc eu préméditation, de la part de son adversaire, en ce qui concerne son action criminelle (cf., p. ex., 41, 10 : $\beta \varepsilon \beta о \cup \lambda \varepsilon \cup \mu \varepsilon ́ v \omega s)$; (c) que ce crime n'a pas de précédents

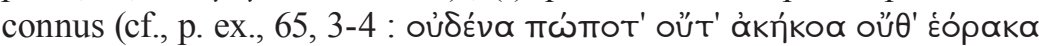

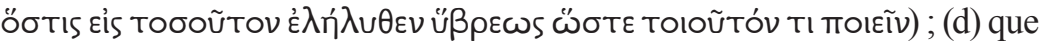
l'attitude de son adversaire est nuisible à l'ensemble des citoyens (cf., p. ex.,

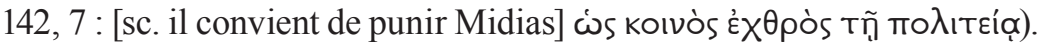

Nous présentons maintenant, dans l'ordre, les préceptes du rhéteur par rapport à ces quatre points et à la série de cas dans le $C$. Midias qui nous paraissent cohérent avec de tels préceptes :

a) Rh. Al., 3, 1426 b 7-8: 'En somme, si tu fais ressortir que ce dont

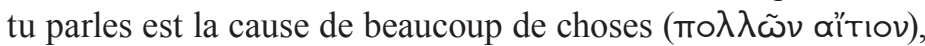
que ce soit des biens ou de maux, cela paraitra grand'; e 4, 1427 a 18-20 : 'Les accusateurs doivent (...) prouver par les moyens

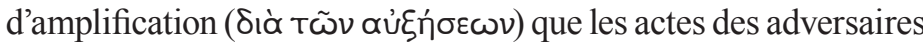
ont été cause de beaucoup de maux (

C. Midias :

[1] (...) j'ai intenté à cet homme (sc. Midias $\left.{ }^{23}\right)$ une plainte pour offense

${ }^{23}$ Dans les citations, sauf indication contraire (qu'elle soit nôtre ou du texte lui-même), les références pronominales seront toutes à Midias. Même ainsi, il nous arrivera de répéter la référence pour plus de clarté. 
à la fête, non seulement à cause des coups qu'il m'a donnés lors des Dionysies, mais encore en raison de bien d'autres brutalités ( $\propto$ $\alpha \lambda \alpha$

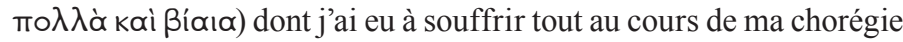

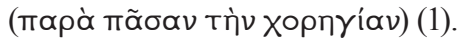

[2] Hé quoi ! Athéniens, alors que vous avez, vous tous, atteint un si haut degré d'humanité et de piété que vous suspendez, pendant ces jours-là, le droit d'obtenir réparation pour des torts antérieurs, Midias, lui, a pu commettre, pendant ces mêmes jours - je vais vous le démontrer - des actes qui méritent les dernières peines! Je veux, après vous avoir montré, un par un (Ěkaotov àm ápXñs), tous les outrages qu'il m’a fait subir, vous parler aussi des coups qu'il m’a portés à la fin : on verra de toute évidence qu'il n'y a pas un seul de ses actes qui ne lui vaille la mort (12).

[3] Les faits qui suivirent et dont je vais vous parler dépassent tout

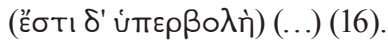

[4] Or cela ne lui a pas suffi (...). Et il ne s'en est pas tenu là dans la violence (...) (17).

[5] (...) il n'a cessé de me faire plus d'ennuis que je ne saurais dire

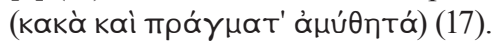

[6] Après avoir tenté d'abord d'acheter le jury des choeurs d'hommes,

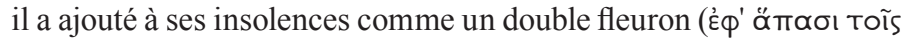

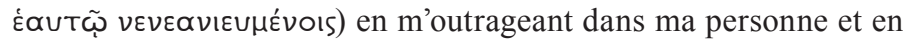
prenant l'entière responsabilité d'arracher la victoire à ma tribu, qui devait l'emporter (18).

[7] Voilà à quels excès d'insolence il s'est porté à mon égard, envers ceux de ma tribu (...); mais il y a encore bien d'autres choses (kai $\pi{ }^{\prime} \lambda \lambda^{\prime}$ ËTEpa) dont je vous parlerai dans le détail (...). Je puis vous citer

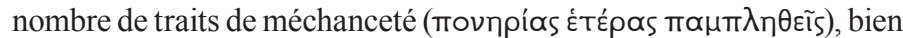
des actes de violence à l'égard de beaucoup d'entre vous ( $\varepsilon i i_{s}$ mo $\lambda \lambda$ oùs

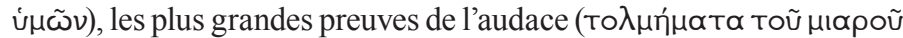

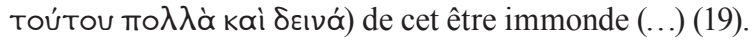

[8] Je pense, Athéniens, que même si je n'avais pas d'autres griefs contre Midias, même si ce que j'ai à dire ne dépassait pas en horreur ce dont je vous ai déjà parlé, vous seriez bien fondés, en tenant seulement compte de ce qui a été dit, à condamner Midias par votre verdict et, dans l'évaluation de la peine, d'aller jusqu'à l'extrême. Mais non ! l'affaire ne s'arrête pas là, et je crois que je ne serai pas à court dans la suite, tant cet homme m'a fourni d'une matière abondante pour

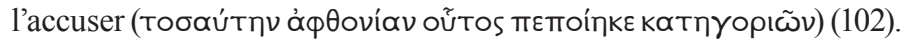

[9] (...) quand il sera convaincu d'avoir commis ces actes en plus (трòs oĩs) des outrages qu'il m'a fait subir pendant ma chorégie, quelle indulgence et quelle pitié sera-t-il en droit d'attendre de vous? (105). 
[10] (...)j’ai eu de la peine à supporter les outrages quej'ai essuyés au cours

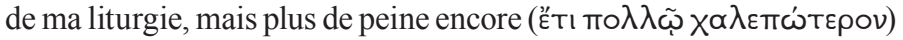
après ce qui devait se produire ensuite, et plus d'indignation. Quelles limites pourrait-on vraiment donner à la méchanceté (108) ? [11] (...) il a commis tant d'injustices à l'égard d'un si grand nombre

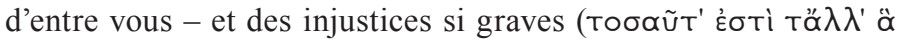

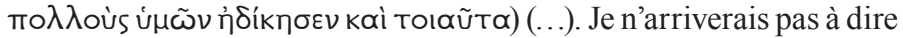

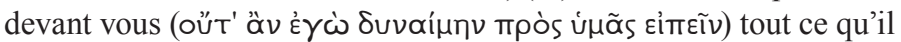
a fait, et vous n'auriez pas la patience de m'écouter (oủ T' à $v$ ú $\mu \varepsilon i ̃ s$

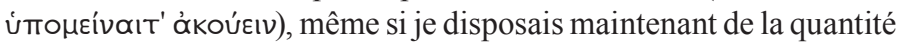
d'eau qu'on nous a impartie à nous deux - toute la mienne et toute

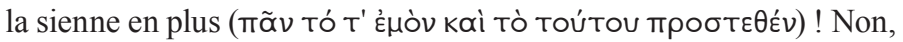
cela ne serait pas suffisant (129) !

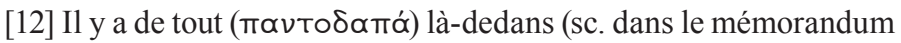
des actes de violence commis par Midias) : des actes de violence en quantité (ü $\beta p \varepsilon ı$ по $\lambda \lambda \propto \alpha i)$, des indélicatesses à l'égard de ses amis, des impiétés envers les Dieux : il n'y a pas un seul développement dans le-

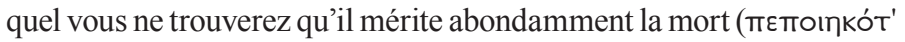

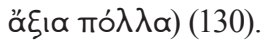

[13] Bien que la vie de cet être impudent et immonde ne soit faite que

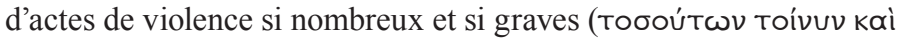

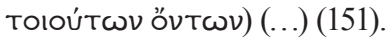

[14] Mais je pense que, même s'il n'y avait pas d'autres raisons, rien que pour les propos qu'il tient publiquement en toute occasion et dans les circonstances où il le fait, il mérite le châtiment suprême (тìv

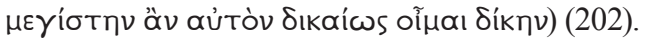

b) Rh. Al., 3, 1426 a 35-42 : 'Voici encore comment tu peux grossir

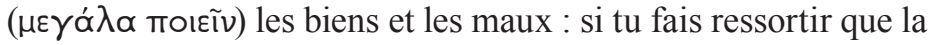

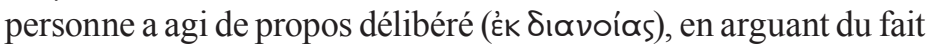

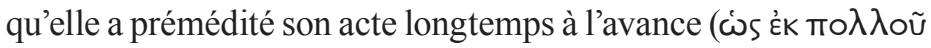
проєvónбєv), qu'elle a projeté d'en faire beaucoup, que l'exécu-

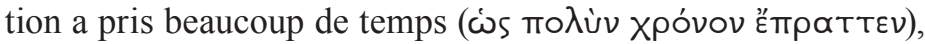

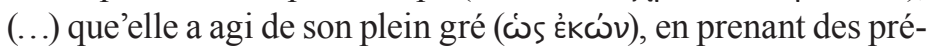
cautions (ف́s દ̇k Tpovoías), et que, si nous agissons tous comme elle, nous serions heureux ou misérables'; e 4, 1427 a 3-5 : 'Il faut surtout montrer qu'il (sc. l'adversaire) a failli de plein gré (ف́s

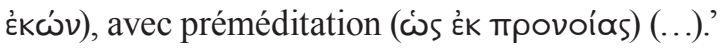

\section{Midias :}

[1] (...) en face d'actes qu'une impulsion subite, allant plus vite que la raison, a pu faire commettre, on peut dire, même s'ils comportent 
l'intention d'outrager, qu'ils ont été commis sous l'empire de la colère : au contraire, quand se fait prendre en flagrant délit un homme qui viole les lois de longue date, constamment, à longueur de journées, non seulement cela n'a rien à voir avec la colère, mais encore c'est une préméditation ( $\beta \varepsilon \beta ం \cup \lambda \varepsilon \cup \mu \varepsilon ́ v \omega \varsigma)$ désormais évidente chez un homme qui se livre à ces violences (41).

[2] (...) j'ai été insulté par un ennemi (et qui n’avait pas bu (vńфovтos)), dès le matin, un ennemi poussé par le besoin d'outrager et non par le

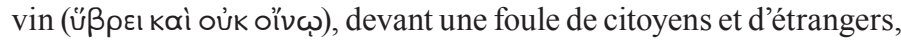
dans une enceinte consacrée où m'appelaient obligatoirement mes fonctions de chorège (74).

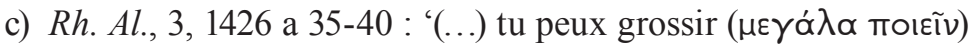
les biens et les maux : si tu fais ressortir que la personne a agi de propos délibéré, en arguant du fait (...) que nul autre avant

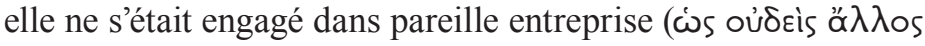

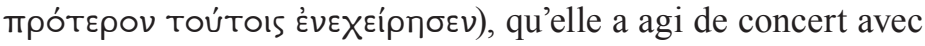
des gens auxquels personne d'autre ne s'était associé, qu'elle a poursuivi des buts que nul autre n'avait recherchés (...).'

\section{Midias :}

[1] (...) j’ai moi-même reçu des coups et essuyé des outrages tels que je ne sache pas que jamais chorège en ait subi jusqu'à ce jour (oî' oủk

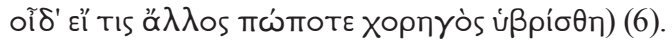

[2] Personne ne peut prétendre avoir jamais entendu dire que personne jusqu'à ce jour ait osé commettre pareil acte dans notre cité

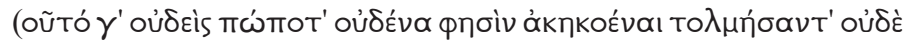

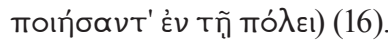

[3] Alors qu'il y a eu tant d'hommes, Athéniens, qui ont été en querelle, non seulement pour de raisons privées, mais aussi pour de motifs politiques, personne jusqu'à ce jour n'a poussé l'impudence assez loin

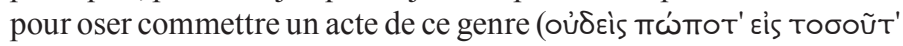

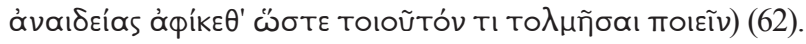

[4] Je pourrais citer bien d'autres que des raisons variées dressaient les uns contre les autres ; mais jusqu'à ce jour on ne m'a cité ni j'ai vu personne qui ait poussé la violence assez loin pour faire rien de

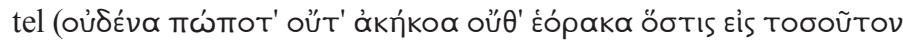

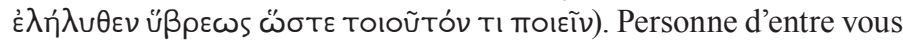

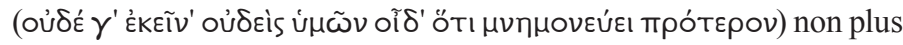
ne pourra se rappeler qu'il y ait eu dans le passé, parmi tant de gens que des inimitiés personnelles ou politiques dressaient les uns contre les autres, un seul homme pour rester planté là au moment de l'appel 
des juges, ni pour leur dicter une formule de serment, d'une façon générale un seul homme qui, dans de semblables circonstances, ait prouvé tant d'hostilité (65).

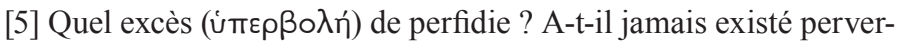

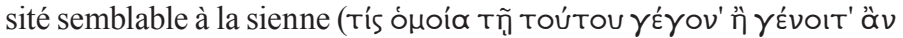
тоипрía), ou pourrait-il en exister (122)?

d) $R h . A l ., 4,1426$ b 29-32 : '(...) il est nécessaire que l'accusateur, quand il accuse de malignité, dise que les actions des adversaires

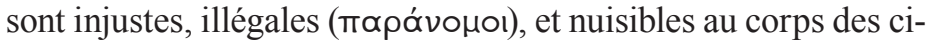

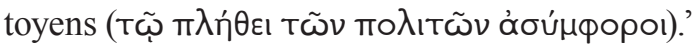

\section{Midias:}

[1] La grossière impudence de Midias et les outrages qu'il fait subir à

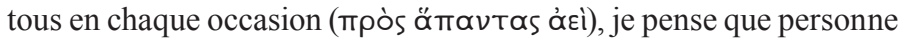
parmi vous, Juges, ni parmi les autres citoyens ne les ignore (1).

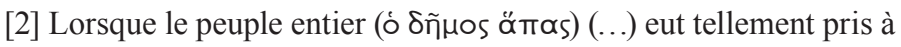
coeur une affaire dans laquelle il se sentait offensé qu'il ne se laissa pas convaicre (...) mais au contraire (...) eut unanimement ( $\mu$ ax

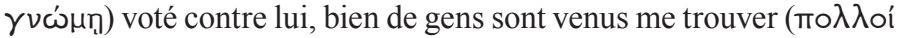

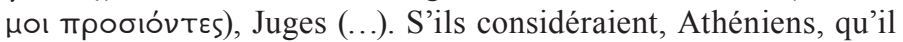
m'avait traité d'une façon indigne, ils voulaient aussi châtier d'autres actes qu'ils avaient vu commettre à cet immonde individu, cet audacieux que rien ne retient plus (2).

[3] (...) j'ai d'autant plus d'espoir d'obtenir justice que sont plus nom-

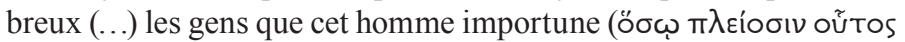
$\eta \dot{\nu} \omega x \lambda \eta \kappa \varepsilon$ ) en leur faisant passer ses mots d'ordre (4).

[4] Voilà donc pourquoi, Juges, je vous demande de me prêter tous une oreille bienveillante; ensuite, quand j'aurai demontré que les outrages

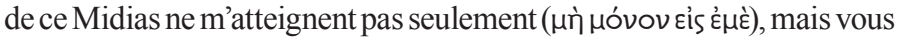

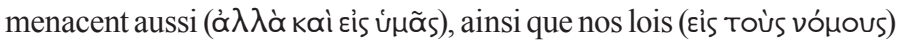
et tous nos concitoyens (Eis toùs ä $\lambda \lambda$ ous äTa $v T \alpha \varsigma$ ), je vous demanderai votre appui dans ma cause, qui est aussi la vôtre (ن่jĩv aủToĩs) (7).

[5] S'il y a jamais eu dans vos rangs des gens por penser que le procès d'aujourd'hui n'était qu'une affaire d'ordre privé, qu'ils se représentent

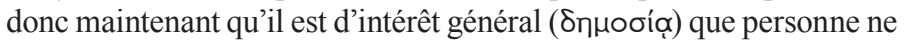
puisse agir ainsi (8).

[6] Pour tant d'injustices prises en bloc fixez une seule peine (...). Je vais d'abord faire la preuve de tous les outrages que j'ai subis, puis de tous ceux que vous (ö $\sigma$ '́ úneĩs) avez essuyés, vous aussi ; ensuite, j'examinerai sa vie dans son entier et je montrerai que ce n'est pas une

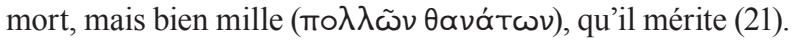


[7] J'ai bien des choses à dire ( $\pi \circ \lambda \lambda \grave{\alpha})$, Athéniens, au sujet des torts qu'il a eus envers les autres (Toùs ö $\lambda \lambda$ ous) (...) ; et j'ai en main un recueil complet de tous les actes de violence et de tous les mépris dont je vous parlerai dans un instant (23).

[8] (...) cet homme (...) a cru pouvoir outrager, non seulement les

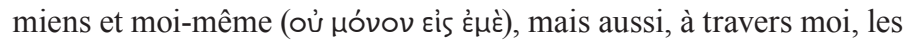
membres de ma tribu (kaì Toùs દ̇uoùs) (81).

[9] (...) vous acquitteriez un homme si dur, si impitoyable, qui a tiré une telle vengeance d'une injustice dont il est seul à se dire la victime (...)? Un homme qui n'a eu égard ni à la fête, ni à la religion, ni à légalité (vómov), ni à rien d'autre, ne le condamnerez-vous pas par votre vote (97)?

[10] (...) je vais parler d'une action atroce, abominable, que cet homme a commise : ce n'est pas seulement une injustice, mais une impiété

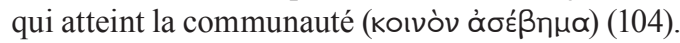

[11] En portant atteinte à mon choeur, il a porté préjudice à ma tribu -

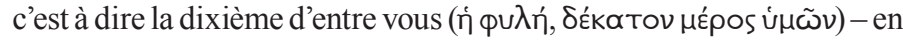
même temps qu'à moi-même; par ses violences préméditées, il a porté préjudice aux lois aussi (oi vómoı), qui sont la sauvegarde de chacun de vous. A tous ces points de vue, le Dieu dont on m'avait constitué le chorège, la Religion sous quelque forme qu'elle se présente, l'auguste puissance de la divinité ont été atteints en même temps que moi (126).

[12] Il faut donc, si vous voulez faire payer à leur juste prix les actes qu'il a commis, considerer dans votre colère, non qu'il ne s'agit que de moi (oủX ஸ́s úmè $v o ́ \mu \omega v)$, la Divinité, la Cité, tout enfin a été en même temps l'objet de ses outrages, et le châtier en conséquence (...) (127).

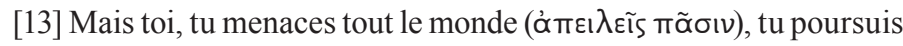
tout le monde de ta fureur ( $\dot{\lambda} \propto \alpha u ́ v \varepsilon 15$ mó́vTas) : tu veux que les autres entrent dans tes vues, mais tu ne fais pas entrer dans les tiennes d'agir sans ennuyer les autres. Voilà ce qui me paraît le signe plus grave, le plus révoltant de ton insolence : tu es monté à la tribune, sale individu,

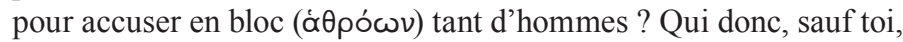
n'aurait pas tremblé d'agir ainsi (135)?

[14] S'il est assez fort pour pouvoir, en agissant comme il le fait, empêcher chacun de nous de tirer de lui une vengeance légitime, vous devez tous, maintenant que vous le tenez, le châtier dans l'intérêt de

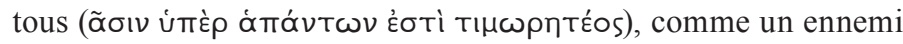

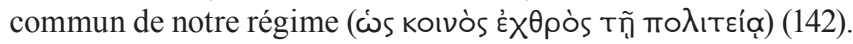

[15] Tout ce qu'il achète par goût de luxe pour lui-même, tout ce superflu, je ne sais pas en quoi cela peut servir à la plupart d'entre vous

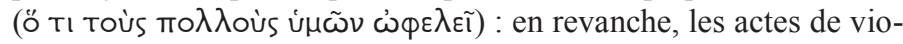
lence qu'il commet, grisé par tout ce luxe, je crois qu'ils atteignent la 


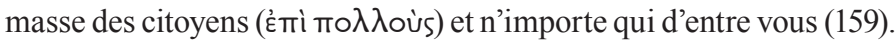
[16] (...) vous (sc. Athéniens) me disiez (...) : 'Vois à pousuivre cet immonde individu! Pas de compromis ! Les Athéniens auront l'oeil sur

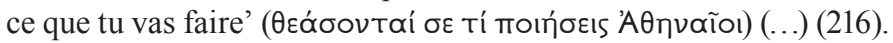

[17] (...) le jugement touche la communauté(koıvì yà ñ kpíoı), comme la touchent tous les délits pour lesquels on le juge aujourd'hui (218).

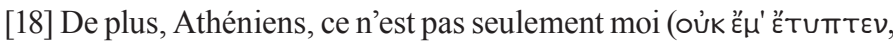

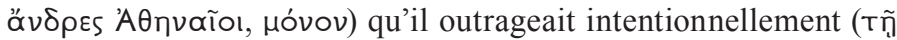

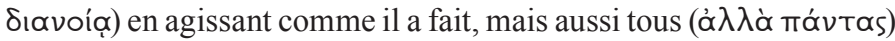
ceux qu'on pourrait croire moins à même que moi d'assurer leur ven-

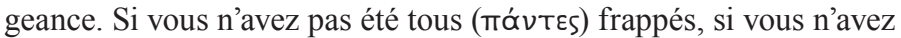

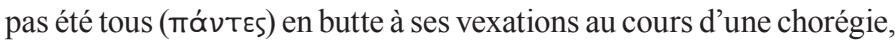
c'est parce que, comme vous savez, vous ne pouvez pas être tous (đ̊ $\mu \alpha$ ாávTEऽ) chorèges à la fois, et qu'un seul homme, rien qu'avec son bras, n'arriverait pas à vous couvrit tous (đ̆ $\pi \propto v \tau \propto \varsigma)$ d'opprobres (219).

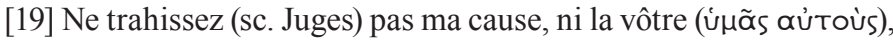
ni celle des lois (Toùs vómous) (222)!

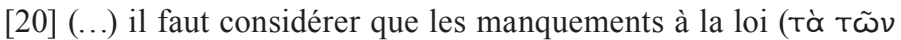

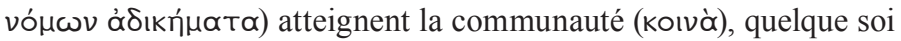
l'homme qui en est convaincu; (...) on ne peut imaginer aucun moyen qui permette à celui qui a transgressé la loi d'échapper à un juste châtiment (225).

\subsubsection{Effet de contraste}

Les préceptes du rhéteur :

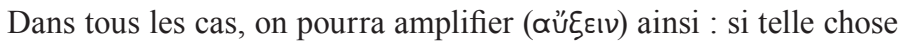
est jugée comme un grand bien, son contraire, si tu le dis, apparaîtra comme un grand mal. De même, si elle est considérée comme un grand mal, si tu dis $<$ son $>$ contraire, cela apparaîtra comme un grand bien $(3,1426$ a $31-35)$.

La témérité des actes perpétrés par Midias apparaît plus grande encore si on la met en contrepoint aux lois qu'elle viole :

Je veux vous faire lire la loi qui fai suite à celle que j'ai citée : elle mettra en pleine lumière à la fois votre prudence ( $\left.\varepsilon u^{\lambda} \lambda \alpha^{\prime} \beta \varepsilon ı \alpha\right)$ et l'audace (Өpóoos) de cet homme (10).

Face à cette loi, l'attitude que l'on attend est celle de la prudence et du respect, - attitude de Démosthène - quand à Midias, on peut s'attendre au contraire : 
Tandis que je considère que je dois agir, prudemment ( $\left.\varepsilon \dot{ }{ }^{\lambda} \alpha \beta \tilde{\omega} \varsigma\right)$, en sui-

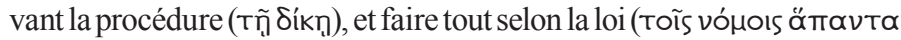
тра́ TTEIV), cet homme (...) a cru pouvoir outrager, non seulement les miens et moi-même, mais aussi, à travers moi, les membres de ma tribu

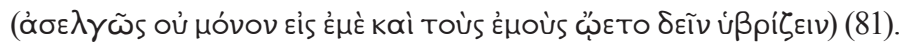

\subsubsection{Effet de compétition}

Il s'agit d'une espèce de relativisme : (a) Démosthène prend un faitexemple connu et qui appartient, dans l'ensemble, à la même catégorie que le fait de Midias qu'il examine dans son discours ; ensuite, les comparant entre eux, il montre sous quels aspects les agissements de Midias sont encore plus graves que l'exemple auquel il peut être comparé ; par ailleurs, ce même type de comparaison peut prendre parfois la forme (b) d'une confrontation entre ce à quoi - du point de vue de la vraisemblance - l'on pourrait s'attendre et ce qui, de fait, s'est produit : qui a eu le plus de raisons pour faire telle chose, ne l'a pas fait, or Midias, qui n'avait pas tant de raisons, l'a fait; ou : qui a eu le plus de raisons pour ne pas faire telle chose, l'a fait ; Midias, par contre, qui n'avait pas les mêmes raisons, ne l'a pas fait ; etc. Deux conséquences découlent de cette comparaison : (1) amplification du caractère criminel de l'attitude de Midias, dans un crime qui - en raison de ses circonstances inhabituelles et aggravantes - en arrive à friser l'invraisemblable ; et, de là, (2) renforcement de l'argument selon lequel il faut appliquer à Midias la peine capitale, souvent en vertu de ce que - dans les exemples présentés - des peines sévères ont été appliquées, ou méritées, pour des crimes pourtant moins graves que celui de Midias ${ }^{24}$. Nous présentons à la suite,

\footnotetext{
${ }^{24}$ Ce renforcement, en conséquence de l'amplification du crime commis, nous fait penser aux lieux communs du possible et de l'impossible, de la grandeur et de la petitesse, telles que les présente Aristote dans la Rhétorique ; il est aussi curieux que, s'agissant de tels lieux, ce soit Isocrate qui soit cité par le Stagirite: cf. II, 1391 b 30-32 : 'En effet, tous les orateurs doivent nécessairement employer aussi dans leurs discours le lieu du possible et de l'impossible (...). En outre, il y a un lieu commun à tous les genres de discours, celui de la grandeur ( $\mu \varepsilon \gamma \varepsilon \dot{\varepsilon} \theta$ ous) : tous les orateurs se servent de la dépréciation ( $\mu \varepsilon ı$ เõv) et de l'amplification ( $\propto$ ứદıv) quand ils conseillent, louent ou blâment, accusent ou défendent'; 1391 b 12-14 : 'Et, si ce qui est plus difficile est possible, ce qui est plus facile l'est de même. Et si une chose est possible à un degré d'excellence et de beauté, elle est également possible à son degré ordinaire : car il est plus difficile de faire une belle maison qu'une maison' ; 1392 b 5-6 : 'Et, si une chose peut être faite sans art et sans préparatifs, à plus forte raison le peut-elle être par l'art et l'application (...)' ; 1392 10-11 : 'Et, si une chose est possible à des inférieurs en capacité, en situation, en intelligence, elle est aussi possible à ceux qui sont supérieurs à ces divers égards ; c'est ainsi qu'Isocrate a dit : “ce qu'Euthynos a pu ap-
} 
dans l'ordre, les préceptes du rhéteur et les cas (a) et (b) présents dans le texte, accompagnés de leurs commentaires respectifs.

Le seconde (mode d'amplification) consiste à présenter un bien - si

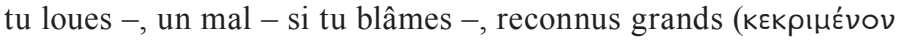
$\mu \varepsilon ́ \gamma \alpha$ ), ensuite à mettre en regard ce dont tu parles, puis à les compa-

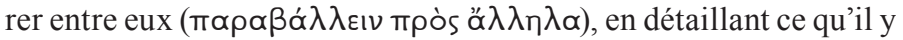
a de plus grand de ton côté et ce qu'il y a de moins grand de l'autre :

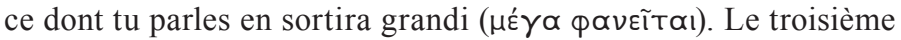

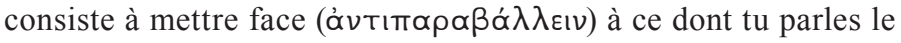
plus infime des éléments qui appartiennent à la même catégorie

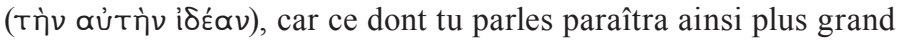

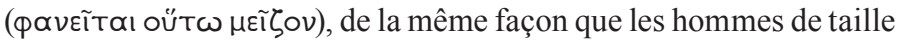
moyenne paraissent grands quand ils se tiennent à côté d'hommes plus petits. (Rh. Al., 3, 1426 a 23-31)

prendre, il serait étrange que, moi, je ne puisse pas le trouver."' (Trad. de Médéric Dufour : Paris, "Les Belles Lettres”, 1991) ; cf., p. ex., Dém., C. Midias, 50 : ‘(...) si les Barbares (...) pouvaient entendre et comprendre ce langage, ne croyez-vous pas qu'ils vous désigneraient tous officiellement pour leurs proxènes? Or une loi qui n'est pas seulement en

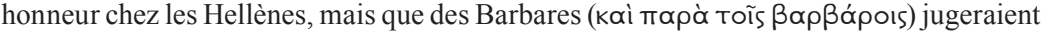
excellente, voyez donc quelle peine méritera justement l'homme qui l'a transgressé !' (Si quelqu'un transgresse une loi que même les barbares reconnaissent, il doit être plus barbare que les barbares eux-mêmes; d'où : si même les barbares reconnaissent la loi que Midias a violée, étant donc prêts à punir celui qui la viole, les Athéniens en auront donc de plus forte raison pour punir Midias.) ; 56-57 : ‘(...) vous savez que, malgré votre volonté d'exclure tout étranger des compétitions, vous n'avez jamais donné à aucun chorège sur les choreutes d'un autre choeur un droit illimité d'interpellation aux fins d'examen de statut (...). Alors ? L'homme qui, conformément la loi (katà tòv vópov), interpelle un choreute, ne s'en

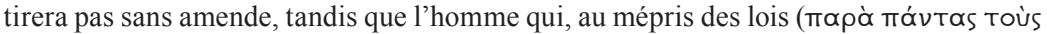
vómous), a frappé un chorège au vu de tous, ne sera pas châtié ?' (Si l'homme qui interpelle un choreute n'est pas libre de réparation légale, même s'il l'a fait dans le cadre de la loi, il n'y en aura que plus de raison pour punir celui qui l'a fait dans l'irrespect le plus total de la loi.) ; 226-227 : 'Vous qui assitiez aux Dionysies, vous avez sifflé cet homme quand il est entré dans le théâtre, vous l'avez hué, vous avez manifesté tous les signes de votre haine,

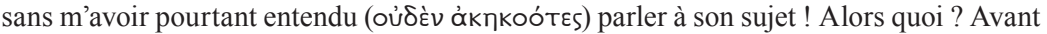

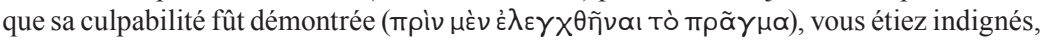
vous poussiez sa victime à la vengeance ; vous applaudissiez quand j'ai déposé la plainte

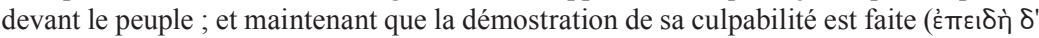
$\xi_{\varepsilon} \xi \lambda \hat{\lambda} \lambda \varepsilon \gamma \mathrm{K}(\alpha \mathrm{l})$, alors que le peuple, siégeant dans un lieu consacré, s'est déjà prononcé contre lui, maintenat que tous les actes de cet immonde individu ont été examinés dans le détail, maintenant que la sort vous a appelés à juger et que vous pouvez en finir par un seul vote, vous hésiteriez maintenant à m'assister, à donner aux autres une leçon de sagesse, à renforcer dans la suite votre sécurité personnelle en faisant de cet homme un exemple pour les autres ?' (Si avant que la culpabilité de Midias soit démontrée, le peuple se prononçait déjà contre lui, il aura encore plus de raison, maintenant que ces crimes ont été soumis à examen, de lui appliquer la punition qui lui est due.) 
Et

Il faut également mettre en regard des actions honorables d'autres

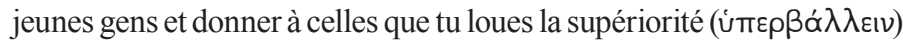
sur celles-là en disant, quand il s'agit de l'autre, les aspects les plus insignifiants de son action, et quand il s'agit de celui que tu loues, les aspects les plus remarquables. ( $R h . A l ., 3,1441$ a 27-30)

a)

1) Dans ce premier exemple, Démosthène pointe pour l'auditoire l'artifice auquel Midias va faire appel, à savoir, la multiplication des exemples ${ }^{25}$, effet de masse dont l'objectif serait, dans le discours de Midias, de compenser l'impossibilité d'une argumentation fondée sur le vraisemblable, étant donné la singularité de l'acte qu'il a pratiqué ${ }^{26}$. Démosthène veut que l'audience en conclue que Midias ne pourra pas recourir à de tels arguments car Midias lui-même, en comparaison (en 'compétition') avec les agresseurs qu'il citerait (celui qui a agressé le thesmothète, et

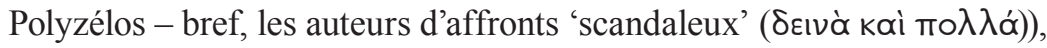
est encore plus criminel, car il ne dispose pas des mêmes atténuants dont pouvaient disposer les autres. L'amplification du crime de Midias a ainsi lieu, par l'attribution d'atténuants aux exemples d'agression auxquels celui-ci pourrait recourir en sa propre faveur ; d'autre part, on peut dire : si de tels affronts sont déjà scandaleux malgré les atténuants qu'ils offrent, encore plus scandaleux est l'affront perpétré par Midias qui ne dispose pas des mêmes atténuants :

On m’a rapporté que Midias allait partout, en questionnant tous les gens qui ont pu être victimes de violences, pour collectionner leurs cas, et qu'ils allaient venir vous raconter leurs histoires : par exemple, celle du proèdre qui, dit-on, fut sous vos yeux frappé naguère par Polyzélos, ou celle du thesmothète qui fut frappé récemment (...) : il se figure que, s'ils vous montre tant d'autres personnes qui ont subi

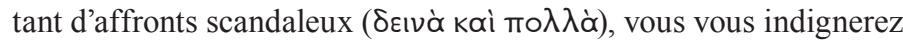
moins devant ce que j'ai enduré moi-même. (...) Qui plus est, nous constaterons que cet homme (sc. Midias) et ces gens-là n'étaient pas à

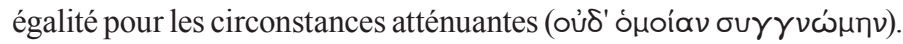
D'abord, l'homme qui avait frappé le thesmothète avait trois excuses : l'ivresse, le désir, l'impossibilité de savoir ce qu'il faisait, puisque l'affaire s'est produit de nuit, dans le noir. En second lieu, Polyzélos a

${ }^{25}$ Cf. commentaire de L. Spengel (Anaximenes..., p. 147) sur ce pas: ... aliorum similia facinora reus haud punita colligit, quibus se quoque defendat...

${ }^{26} \mathrm{Cf}$., à ce sujet, $R h . A l ., 8,1429$ a 22 sq. 
déclaré que la violence de son tempérament impulsif, allant plus vite que la raison, l'avait poussé à cet acte : il n'était pas l'ennemi personnel de la victime, et n'a pas agi avec l'intention d'outrager (oú $\delta$ ' $\dot{\varphi} \varphi^{\prime}$

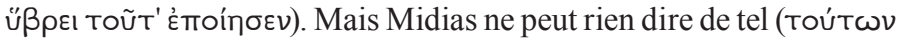

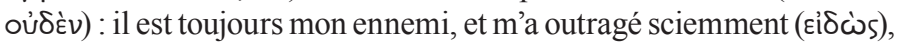
en plein jour : et ce n'est pas seulement en cette occasion, mais en

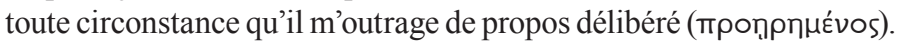

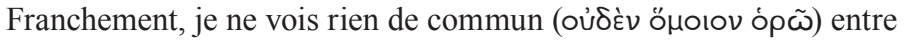
la situation de ces gens et la mienne (36-39).

2) En un autre pas en avant, Démosthène compare sa situation à celle d'Evéon : tout comme Démosthène a été agressé par Midias, Evéon l'a été par Boeôtos ; mais la série d'atténuants que Démosthène pointe dans l'attitude de ce dernier, accompagnée de la série des aggravants correspondants dans l'agression pratiquée par Midias, donne à cette dernière un relief d'autant plus saillant ; de plus, en rappelant qu'Evéon - en raison d'un seul coup reçu - a tué Boeôtos, Démosthène veut amener l'auditoire à conclure que a) la peine pour outrage (et non le simple coup) - crime intolérable - doit être maximale ; et que b) lui, Démosthène - bien qu'il approuve la conduite de ceux qui, dans ce cas, font justice de leurs propres mains - s'est montré un esprit modéré en se contentant d'intenter un procès à Midias. Son raisonnement est : si l'on peut considérer juste l'attitude d'Evéon, qui - malgré tous les atténuants de l'agression dont il fut victime - punit son agresseur de la mort, on devrait attendre une punition encore plus rigoureuse pour Midias, qui ne bénéficie pas de tels atténuants :

On ne peut pas dire non plus que je profite du fait que le scandale est

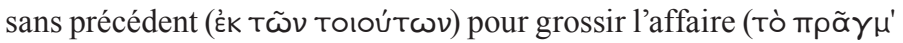

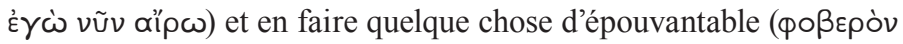

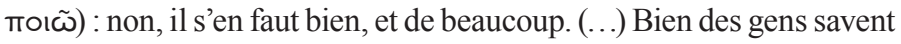
qu'Evéon, le frère de Léodamas, tua Boeôtos dans un repas qui réunissait des amis, pour un seul coup reçu. Ce n'est pas le coup qui provoque l'indignation, mais l'intention de déshonorer : pour un homme libre, le scandale n'est pas d'être frappé, si scandaleux soit-il, mais de l'être de façon outrageante. (...) Réfléchissez, Athéniens, au nom de Zeus et des Dieux, et demandez-vous en vous-mêmes si je n'étais pas beaucoup plus fondé à me laisser aller à ma colère (ö $\sigma \omega \pi \lambda \varepsilon^{\prime}$ ov $^{\prime}$

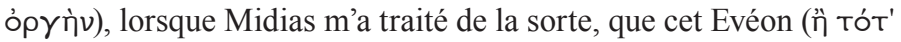

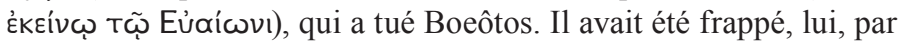

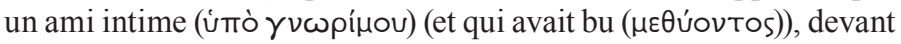
six ou sept personnes, qui étaient aussi ses amis ; ceux-ci devaient reprocher à l'un son acte, et féliciter l'autre d'avoir pu se contenir et 
supporter l'affront; de plus, il était allé souper dans une maison où il

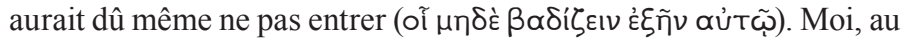

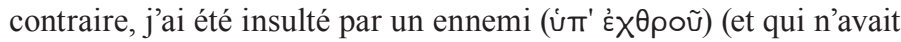
pas bu (vńфovтos)), dès le matin, un ennemi poussé par le besoin

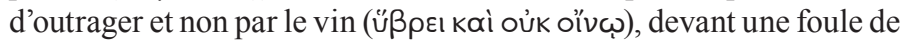
citoyens et d'étrangers, dans une enceinte consacrée où m'appelaient

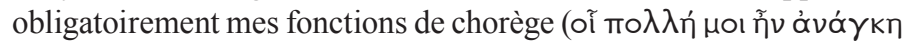

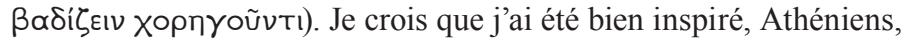
grâce à mon sang-froid ou plutôt à ma bonne étoile, de me contenir sur le moment et de ne pas me laisser entraîner à un acte irréparable :

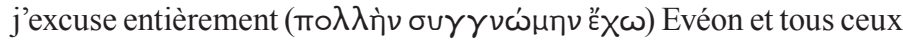
qui, devant l'outrage, se sont fait justice eux-mêmes (70-74).

Que l'on compare :

I)

\begin{tabular}{|c|c|c|}
\hline \multicolumn{2}{|l|}{ Boeôtos } & Midias \\
\hline $\begin{array}{l}\text { a agressé Evéon } \\
\text { atténuants : }\end{array}$ & $=$ & $\begin{array}{l}\text { a agressé Démosthène } \\
\text { aggravants : }\end{array}$ \\
\hline $\begin{array}{r}\text { - Boeôtos était son ami } \\
\text { intime }\end{array}$ & $<$ & $\begin{array}{l}\text { - Midias était son ennemi } \\
\text { personnel }\end{array}$ \\
\hline - Boeôtos avait bu & $<$ & 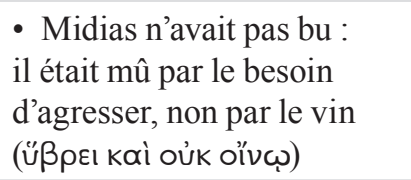 \\
\hline $\begin{array}{r}\text { - Boeôtos l'a agressé devant } \\
\text { quelques amis seulement }\end{array}$ & $<$ & $\begin{array}{l}\text { - Midias l'a outragé devant } \\
\text { une foule de citoyens et } \\
\text { d'étrangers }\end{array}$ \\
\hline $\begin{array}{r}\text { • Evéon n'aurait pas dû } \\
\text { entrer dans la maison où il } \\
\text { était entré, qui n'était pas } \\
\text { respectable }\end{array}$ & $<$ & $\begin{array}{l}\text { - Démosthène a été agressé } \\
\text { dans une enceinte sacrée, où } \\
\text { il se trouvait par obligation }\end{array}$ \\
\hline
\end{tabular}

II)

\begin{aligned} Evéon & Démosthène \\ \hline $\begin{array}{r}\text { a été outragé par Boeôtos } \\ \text { (mêmes atténuants) }\end{array} & =\begin{array}{l}\text { a été outragé par Midias } \\ \text { (mêmes aggravants) }\end{array} \\$\[ \begin{array}{l}\text { attitude prise : } \\ \text { il tue Boeôtos }\end{array} \]$ & <\begin{array}{l}\text { attitude prise : } \\ \text { il intente un procès à Midias }\end{array}\end{aligned}$


3) Démosthène compare aussi Alcibiade et Midias, les égalant, en un premier 'axe', en trois points : (1) le premier a frappé Tauréas, qui était chorège ; le second a frappé Démosthène, également chorège ; (2) le premier a fait arrêter le peintre Agatharque ; le second a fait subir l'atimie au juge Straton ; (3) le premier a mutilé les images de Hermès ; le second a cherché à détruire totalement les ornements sacrés. Cependant Démos-

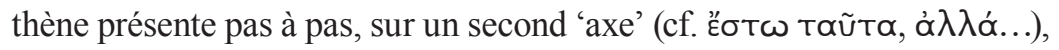
les atténuants pour l'affaire Alcibiade : (1) il y avait conditions d'égalité entre Alcibiade et Tauréas, car tous deux étaient chorèges, et l'attitude d'Alcibiade ne transgressait aucune loi ; (2) Alcibiade a surpris Agatharque en flagrant délit ; (3) bien que sacrilège, la mutilation des images est moins grave que la destruction totale ${ }^{27}$ d'ornements sacrés. Ces atténuants nous rappellent quels sont, de la part de Midias, les aggravants de son attitude : (1) Midias, n'étant pas chorège, n'était pas en condition d'égalité avec Démosthène, qui lui l'était : en l'agressant il violait les lois ; (2) Straton n'avait commis aucun délit; (3) détruire les ornements sacrés est une faute plus grave que la mutilation des images d'Hermès. On perçoit dès lors que l'égalité initiale est défaite moyennant la présentation d'atténuants, d'une part, qui nous rappelle, d'autre part, les aggravants, de façon à ce que la conduite agressive de Midias se trouve ainsi amplifiée par rapport à celle d'Alcibiade ; de surcroît Démosthène dit que, bien qu'Alcibiade ait eu de nombreux titres de reconnaissance populaire, les ancêtres - même devant de tels atténuants - ne l'en ont pas moins châtié ; or, Midias non seulement ne peut bénéficier d'atténuants, mais de plus, selon Démosthène, il n'inspire pas la sympathie ${ }^{28}$, ni ne peut présenter de grands services à la communauté29. Conclusion : si, même dans de telles conditions, les ancêtres ont considéré juste de bannir un criminel comme Alcibiade, il serait donc encore plus juste de punir Midias, car il est encore plus criminel :

L'histoire nous apprend que jadis, aux temps anciens où Athènes était prospère, a vécu Alcibiade ; or considérez comment nos aïeux en usèrent avec un homme qui avait tant de titres à la reconnaissance populaire, lorsqu'il se crut en droit d'être odieux et brutal. (...) il avait lui-même pris deux fois les armes pour défendre à Samos la cause

\footnotetext{
${ }^{27}$ Démosthène, ici, prend - pour que l'amplification soit possible, évidemment, - l'extension intentionnelle, et non réelle, du crime de Midias ; cf. C. Midias, 16 : ‘(...) le vêtement consacré (...) et aussi les couronnes d'or que j'avais fait faire pour l'éclat de mon choeur, voilà ce

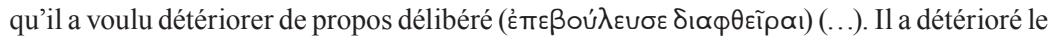

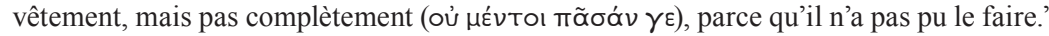
${ }^{28}$ Cf., p. ex., ib., 198.

${ }^{29}$ Cf. ib., 154 sq.
} 
de la démocratie, et une troisième fois ici-même ; il avait prouvé son

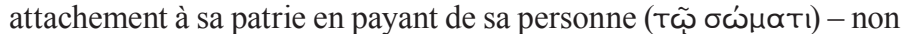

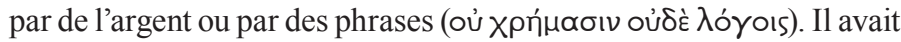
aussi pour lui ses participations aux Jeux Olympiques, ses victoires, ses couronnes : excellent général, d'ailleurs, il passait, dit-on, pour le meilleur orateur de son temps. Pourtant ( $\dot{\alpha} \lambda \lambda^{\prime}$ ö $\left.\mu \omega \varsigma\right)$ nos lointains aïeux ne lui concédèrent point, pour aucun de ses mérites, le droit de les outrager : au contraire, faisant de lui un banni, ils le chassèrent ; et (...) ils endurèrent tout, pensant qu'il valait mieux subir n'importe quoi, en résistant, que d'admettre qu'on leur fît outrage eux l'acceptant. D'ailleurs s'est-il livré à des violences aussi graves que (TocoũTov... í $\lambda$ íkov...) celles dont cet homme-ci est maintenant convaicu ? - Il a frappé en pleine figure Tauréas, qui était chorège. Je l'accorde, mais

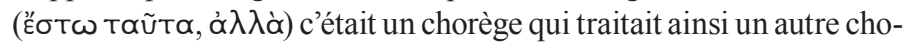
rège, et il ne pouvait pas encore violer la loi de maintenant. - Il a fait jeter en prison le peintre Agatharque à ce qu'on dit. - Oui, mais il

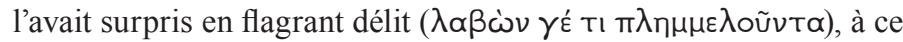
qu'on dit aussi ; ce qui fait que cela ne vaut pas la peine de lui en faire reproche. - Il a mutilé les Hermès. - Tous les actes sacrilèges (öா

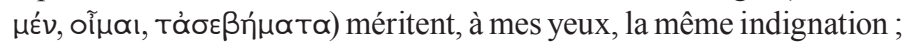
mais la destruction (Tò $\delta$ ' ö $\lambda \omega s$ à $q \alpha v i \zeta \varepsilon ı$ ) totale d'ornements sacrés, c'est autre chose qu'une telle mutilation (143-147) !

Que l'on compare :

\begin{tabular}{|c|c|c|}
\hline Alcibiade & & Midias \\
\hline $\begin{array}{r}\text { il a frappé Tauréas, } \\
\text { qui était chorège } \\
\text { atténuants : }\end{array}$ & $=$ & $\begin{array}{l}\text { il a frappé Démosthène, } \\
\text { qui était chorège } \\
\text { aggravants : }\end{array}$ \\
\hline $\begin{array}{l}\text { - c'était un chorège qui } \\
\text { traitait ainsi un autre chorège } \\
\text { (égalité de conditions) }\end{array}$ & $<$ & $\begin{array}{l}\text { - il n'était pas chorège : } \\
\text { Midias devait respecter le } \\
\text { chorège Démosthène }\end{array}$ \\
\hline $\begin{array}{r}\text { - il ne pouvait pas violer } \\
\text { la loi actuelle }\end{array}$ & $<$ & - il a violé les lois actuelles \\
\hline $\begin{array}{r}\text { il a fait arrêter le peintre } \\
\text { Agatharque } \\
\text { atténuants : }\end{array}$ & $=$ & $\begin{array}{l}\text { il a soumis à l'atimie le juge } \\
\text { Straton } \\
\text { aggravants : }\end{array}$ \\
\hline - il l'a surpris en flagrant & $<$ & $\begin{array}{l}\text { - Straton n'avait commis } \\
\text { aucun délit }\end{array}$ \\
\hline
\end{tabular}




\begin{aligned} & il a mutilé les Hermès $\begin{array}{l}\text { il a détruit les ornements } \\ \text { sacrés } \\ \text { aggravants : }\end{array} \\ & \begin{array}{r}\text { atténuantes : } \\ \text { mais la mutilation est moins } \\ \text { grave que la destruction des } \\ \text { ornements sacrés }\end{array}<\begin{array}{l}\text { ornements sacrés est plus } \\ \text { grave que la mutilation }\end{array} \\ &$\hline\end{aligned}

4) De même, s'il a été considéré juste de condamner à mort des hommes dont la conduite a été moins révoltante que celle de Midias, à plus forte raison il faudra appliquer à celui-ci la peine maximale :

Je veux vous citer, Athéniens, ceux qu'à la suite d'un vote du peuple vous avez condamnés pour outrage à la fête et montrer ce qu'avaient fait quelques-uns d'entre eux pour encourir votre colère (et quelle colère !),

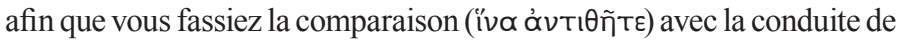
cet homme-là (sc. Midias). [Dans la suite, Démosthène cite l'exemple de Evandre de Thespies (175-7), celui du père de l'archonte Charicleidès (178-9), et celui de Ctésiclès (180).] Hé bien ! Athéniens, la conduite de ces hommes dont l'un (sc. le père de Charicleidès) a perdu le bénéfice de droits acquis, dont l'autre (sc. Ctésiclès) a été condamné à mort fut

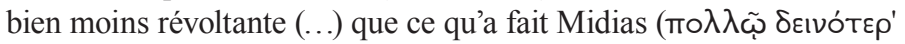

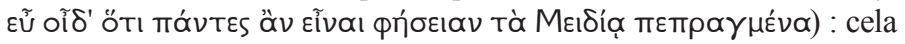
ne se passait pas dans une procession; il n'avait pas eu gain de cause ; il n'avait d'autre raison que sa brutalité quand il a agi comme il l'a fait. Laisson de côté tous ces cas : mais Pyrrhus l'Etéoboutade, certains d'entre vous ont cru devoir le condamner à mort quand il fut dénoncé pour remplir des fonctions de juge tout en étant débiteur envers l'État : frappé par votre tribunal, il fut mis à mort. Pourtant (kaítol) ce salaire,

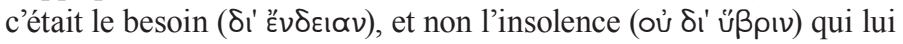
faisait le rechercher. Je pourrais en citer bien d'autres (kai mo $\lambda \lambda$ oùs à

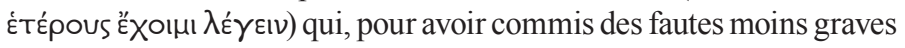

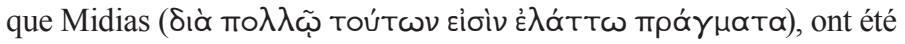
condamnés à mort ou frappés d'indignité civique (175-182).

b)

1) Démosthène compare la situation de Midias à celle des chorèges qui voulaient empêcher Théozotidès, ainsi qu'à celle de ceux qui voulaient empêcher Aristide. Ces chorèges - qui avaient dépensé de l'argent et voulaient remporter la compétition -, avaient des raisons de vouloir les empêcher - bien que Démosthène ne fasse qu'effleurer le sujet ${ }^{30}$ - et avaient,

${ }^{30} \mathrm{Cf}$. note suivante. 
pour ce faire, la loi à leurs côtés ; mais, devant le théâtre plein, et en respect à la religion, ils se continrent (même si pour certains il s'agissait d'attaquer un ennemi personnel). Or, face à une telle démonstration de piété, l'acte de

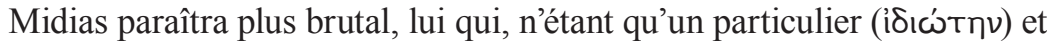
n'ayant pas dépensé un sou, sous le prétexte d'attaquer un ennemi personnel, $\mathrm{a}$ - sans considération pour la fête ou pour les lois - assailli Démosthène, homme estimé, chorège, qui avait dépensé tout ce qu'il avait ${ }^{31}$ :

(...) il y a un nommé Sannion, l'entraîneur des choeurs tragiques : condamné pour refus d'appel, cet homme a eu des malheurs. Après ce triste événement, un chorège tragique - c'était, je crois bien, Théozotidès - plein d'une noble ambition l'engagea à son service. Au début, les autres chorèges, ses rivaux, étaient dans l'indignation et disaient qu'ils l'empêcheraient de travailler ; mais ensuite, voyant le théâtre rempli par tout ce monde venu en masse pour le concours, ils hésitèrent et le laissèrent faire : personne ne lui chercha querelle ; au contraire,

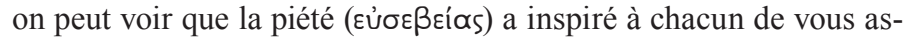
sez d'indulgence pour qu'il lui fût possible, après cela, d'entraîner des choeurs sans que même un ennemi personnel cherchât à l'empêcher de travailler : encore bien moins un chorège (TO०OŨT' áméx

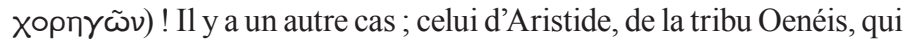
a connu les mêmes deboires, lui aussi (...). La nécessité de lui mettre eux-mêmes (sc. les autres chorèges) la main au collet, sans pouvoir le citer devant l'archonte comme s'il se fût agi d'un étranger, a fait hésiter chacun d'eux, et ils n'ont pas voulu procéder aux yeux de tous, de leurs

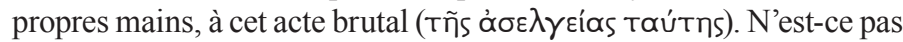
là, Juges, un scandale et une pitié ? Parmi tous ces chorèges qui auraient pu penser remporter la victoire en recourant à ce moyen (...) il ne s'en

${ }^{31}$ Quand Démosthène, sur ce point, s'attribue à lui-même ces qualités, il contribue d'une part à l'amplification des délits de Midias ; d'autre part, cette amplification semble supposer, de plus, une comparaison entre celui qui ne méritait pas (de par sa condition d'homme 'estimé', de chorège), un affront et, pourtant, en a été victime (Démosthène), et d'autres ceux qui, n'en n'ayant pas été victimes (Théozotidès / Sannion, Aristide), auraient mérité, si ce n'est un tel affront, pour le moins une interpellation dans le cadre de la loi. Mais c'est là un point qui - bien qu'il paraisse faire partie du tableau de la comparaison entre l'attitude impie de Midias et celle, de piété, des chorèges, ne peut être développée à fond par Démosthène : cf. 58 : 'Je vous demande de ne pas m'en vouloir si je cite avec leur nom quelques personnes qui ont eu des malheurs. Non, par les Dieux ! ce n'est certes pas l'intention de blesser qui me fait parler, ni le désir de dire à personne des choses pénibles (...). Ainsi, il y a un nommé Sannion, l'entraîneur des choeurs tragiques : condamné pour refus d'appel, cet homme a eu des malheurs' ; cf. aussi la note de J. Humbert (ib., p. 182) : 'Cet euphémisme [sc. "cet homme a eu des malheurs"] voile l'atimie qui, dans le cas présent, avait frappé Sannion pour s'être volontairement dérobé à ses devoirs militaires. De ce fait, il était assimilé à un étranger et exclu de toute participation aux concours'. 
est pas trouvé un seul pour oser porter la main sur un de ces hommes, alors que la loi les y autorisait, mais au contraire ils ont montré tant de discrétion, tant de piété, tant de modération que, malgré leurs dépenses, en dépit de l'ardeur de la compétition, ils non pas voulu agir ainsi : et

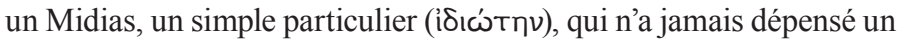
sou, porrait, sous prétexte qu'il se heurte à un ennemi personnel, traîner dans la boue et frapper un homme considéré, un chorège, qui dépense tout ce qu'il a - et cela, sans se soucier de la fête, ni de vos lois, ni de votre opinion, ni du Dieu (58-61)!

2) La comparaison est maintenant entre des querelles connues (cf. 62,

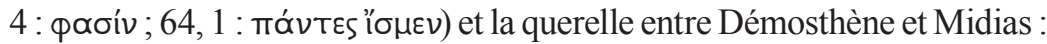
par exemple, malgré l'extrême inimitié entre Iphicrate et Dioclès, et bien que ce dernier soit en concurrence avec le père du premier pour la chorégie, Iphicrate, qui pourtant pouvait compter sur les ressources de l'argent et des amis, n'a pas pratiqué les actes que Midias a pratiqués (tentative de détruire les ornements et les vêtements, de suborner l'entraîneur des chœurs; le fait d'avoir dicté la formule de serment aux juges ${ }^{32}$, etc.) : Iphicrate s'est incliné devant la loi, se résignant à voir son ennemi victorieux. Or devant de tels exemples, il faut reconnaître que - la querelle opposant Midias à Démosthène n'étant pas plus grande que celle qui a existé entre Iphicrate et Dioclès (ni que celle entre Philostrate de Colone et Chabrias) - Midias a agi de forme disproportionnée et, donc, insolite :

Alors qu'il y a tant d'hommes, Athéniens, qui ont été en querelle, non seulement pour des raisons privées, mais ausi pour des motifs politiques, personne jusqu'à ce jour n'a poussé l'impudence assez loin pour oser commettre un acte de ce genre. Pourtant, à ce qu'on dit

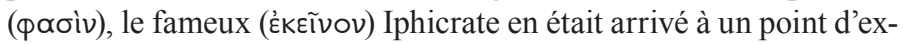

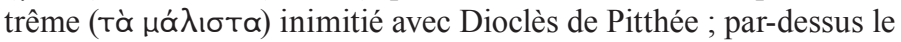
marché, il se produisit que Tisias, père d'Iphicrate, fut le concurrent de Dioclès dans sa chorégie. Malgré tout ( $\dot{\alpha} \lambda \lambda^{\prime}$ ö $\left.\mu \omega \varsigma\right)$, Iphicrate, qui avait beaucoup d'amis et beacoup d'argent, qui avait de lui-même une haute opinion fondée sur la gloire et sur les honneurs dont vous l'aviez jugé digne, n'a pas pénétré nuitamment chez les orfèvres, n'a pas cherché à détériorer les vêtements préparés pour la fête, n’a pas tenté de soudoyer l'entraîneur des choeurs, n'a pas gêné les répetitions,

\footnotetext{
${ }^{32} \mathrm{Cf}$. le second argument, 4 : '(...) pendant que les juges du concours s'engageaient par serment à donner la palme à celui dont les choeurs auraient le mieux chanté, Midias dit, pour les piquer... "à l'exeption de Démosthène" '; cf. aussi la note de J. Humbert (ib., p. 182) : 'Démosthène force son expression, sans doute à dessein : Midias a dû dire en a parte, mais peut-être assez haute pour être entendu (...)'.
} 


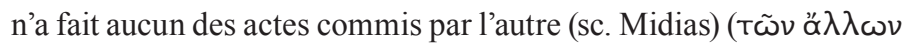

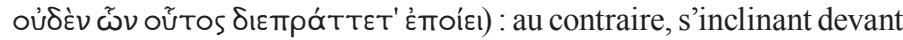

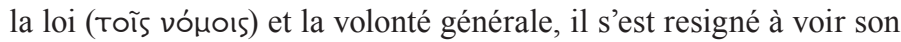

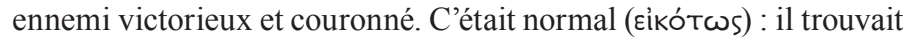
légitime de faire ces concessions au régime sous lequel il avait le bon-

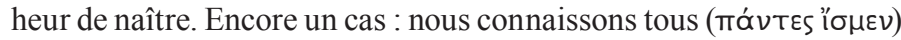
Philostrate de Colone, celui qui a intenté à Chabrias une action capitale à propos des affaires d'Oropos ; il n'y avait pas accusateur plus

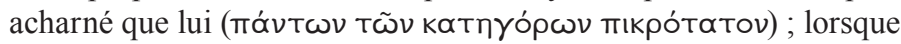
après cela il fut chorège aux Dionysies pour les choeurs d'enfants, il ne vit pas Chabrias lever la main sur lui, ni lui arracher sa couronne, ni se laisser aller à aucune manifestation déplacée. Je pourrais citer bien d'autres que des raisons variées dressaient les uns contre les autres ; mais jusqu'à ce jour on ne m'a cité ni j'ai vu personne qui ait poussé la violence assez loin pour faire rien de tel. Personne d'entre vous non plus ne pourra se rappeler qu'il y ait eu dans le passé, parmi tant de gens que des inimitiés personnelles ou politiques dressaient les uns contre les autres, un seul homme pour rester planté là au moment de l'appel des juges, ni pour leur dicter une formule de serment, d'une façon générale un seul homme qui, dans de semblables

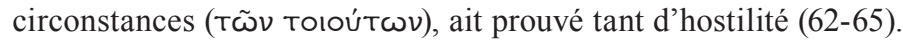

3) Démosthène procède également à une opposition entre lui et Midias. Cette antithèse a un effet double : (1) amplifier les actions du premier par le biais d'une comparaison qui (2) rabaisse les actions du second. Démosthène établit des points d'égalité entre Midias et lui pour les rompre ensuite tous : quant à l'exercice des liturgies, par exemple, tous deux l'ont fait, mais Midias, bien que plus âgé que Démosthène, en a assuré moins que lui ; Démosthène a été triérarque très tôt, quand les frais étaient beaucoup plus élevés ; Midias n'a assumé une liturgie qu’à partir du moment où l'État a pris en charge une partie des frais ; Midias

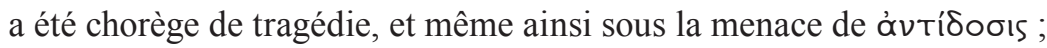
Démosthène, par contre, a été chorège bénévolement, pour les flûtistes des chœurs des adultes ; Midias, bien qu'ayant hérité d'une grande fortune, n'a pas été président de symmorie ; Démosthène l'a été bien qu'il ait été dépouillé par ses tuteurs ; etc. Le tableau, ainsi, est fait selon le raisonnement suivant : moi, Démosthène, étant moins (en âge, en biens, etc.) que Midias, j'ai fait plus que lui, qui était plus que moi (en âge, en biens, etc.) (d'où se rabaissent les actions de Midias en comparaison avec celles de Démosthène). Il y a, dans ce raisonnement, la présupposition vraisemblable que celui qui a le plus de conditions de faire les choses doit, pour cette raison, en faire plus et mieux que celui qui ne dispose 
pas des mêmes conditions ${ }^{33}$. Ainsi pour rabaisser les actions de Midias, Démosthène tout en amplifiant ses propres actions, veut montrer que son adversaire en fait moins, selon la vraisemblance, qu'il ne devrait en faire :

(...) s'il faut regarder de près en quoi consistent réellement ces liturgies, voici ce que je veux vous dire. Et considerez avec quelle impartialité

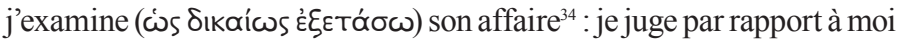

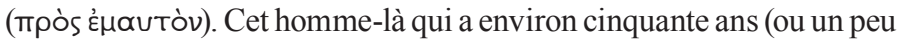

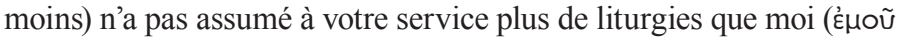

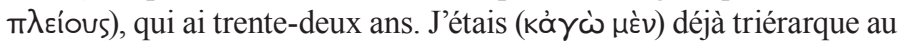
sortir de l'enfance, dans un temps où, nous les triérarques, nous étions solidairement responsables par deux pour faire face de nos deniers à toutes les dépenses et pour fournir aux navires leurs équipages : lui au contraire (oưTos $\delta$ É), quand il avait l'âge que j'ai aujourd'hui, il n'avait

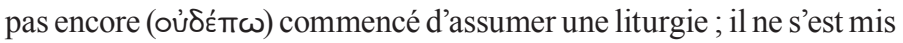
à en tâter que depuis que vous avez créé douze cents contribuables ; vous leur demandez un talent et, avec ce talent, ils font les frais de la triérarchie ; après cela, l'État paie l'équipage, fournit le matériel, tant et si bien qu'il arrive à ces gens-là de ne dépenser réellement rien du tout et même, avec l'air d'avoir assumé une liturgie, de se faire exempter des autres liturgies. Hé bien ! en est-il autrement? Il a été chorège pour la tragédie, moi pour les flûtistes des choeurs d'adultes, et personne n'ignore que, dans le seconde cas, les dépenses sont bien plus considé-

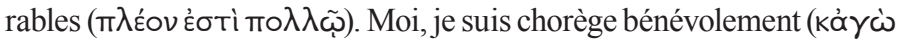

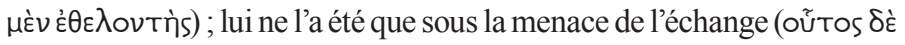

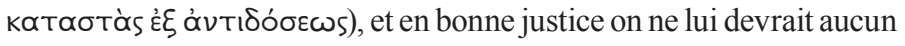
gré. Quoi encore ? J'ai offert un banquet à ma tribu et j'ai été chorège pour les Panathénés ; lui n'a fait ni l'un ni l'autre. J'ai été pendant dix ans président de symmorie, à égalité avec Phormion, Lysithéidès, Callaischros et les plus riches ; pour l'impôt, j'étais taxé, non sur ma fortune

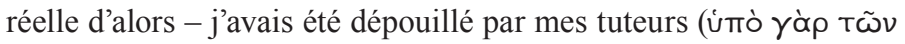

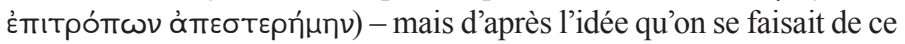
que mon père m'avait laissé et que je devais légitimement retrouver à ma majorité. Voilà ce qu'a été ma conduite anvers vous; et Midias? Jamais jusqu'à ce jour - sans que personne l'eût dépouillé de son patrimoine

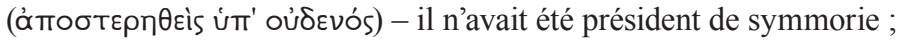

${ }^{33}$ Cf. Rh. Al., 35, 1441 a 32-37 : 'Il faut aussi amplifier les actions à l'aide des vraisemblances, comme ceci : “À coup sûr, qui, si jeune, s'est montré philosophe, était promis à faire, avec l'âge, de grands progrès" ou : "À coup sûr, qui supporte avec constance les peines du gymnase s'adonnera avec amour aux labeurs de la philosophie". C'est de cette manière que nous amplifierons à l'aide des vraisemblances.'

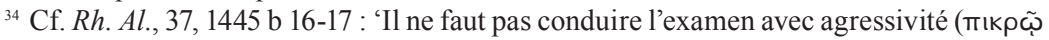

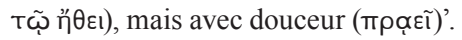


pourtant ( $(\dot{\alpha} \lambda \lambda \dot{\alpha})$ il a hérité de son père une grosse fortune. Où est sa magnificence ? Où sont les liturgies, les libéralités impressionnantes dont il se vante (154-157)?

4) Même raisonnement que dans l'exemple précédent : Démosthène veut montrer que Midias a fait preuve de sa lâcheté, lâcheté dont n'a pas été affligé celui qui, selon la vraisemblance (en raison de sa débilité physique) aurait pu l'être :

(...) lorsque le stratège Phocion eut fait appel aux cavaliers d'Argoura en vue d'une relève et que Midias se vit pris au piège de toutes ses finesses, ce maudit pleutre abandonne son corps et s'embarque sur le navire, au lieu de partir avec les cavaliers dont il avait revendiqué le commandement quand ils étaient ici. S'il y avait quelque danger sur mer, il est visible qu'il aurait choisi la voie de terre ! Non, il ne s'est pas conduit ainsi

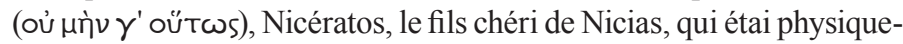

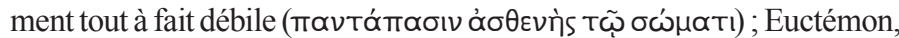
fils d'Aesion, n'a pas non plus agi ainsi (oủx oút $\omega$ ), ni Euthydème, fils de Stratoclès ; au contraire (’̊ $\lambda \lambda \dot{\alpha})$ chacun d'eux, après avoir de grand coeur (غ̇kઢ̀v) donné une trière, loin de profiter de l'occasion pour se dérober à ses obligations militaires, a fourni gracieusement à l'État une trière prête à prendre la mer et a payé lui-même de sa personne dans le poste même que lui avait assigné la loi. Mais ce n'est pas la même chose avec l'hipparque Midias ! Il abandonne le poste que lui assignaient les lois, et va mettre au nombre des services qu'il a rendu à l'État des manoeuvres dont il devra rendre raison (164-166).

\subsubsection{Omission (pleine ${ }^{35}$ ): prétérition et sous-entendu}

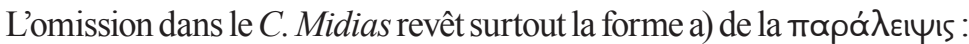
l'orateur feint de ne pas dire ce qu'il dit effectivement, ou bien la forme b) d'une omission 'partielle' s'il est possible de l'appeler ainsi : l'orateur effectivement ne dit pas une chose, mais se contente de la suggérer, évitant de la nommer directement. Ainsi, il grossit sa matière non seulement parce qu'il fait paraître qu'il en a long à dire (ce qui est un effet essentiellement quantitatif, sur le volume), mais surtout parce que, jouant avec l'imagination de l'auditoire, il profite de la tendance de celui-ci à la généralisation et à l'abus dans l'interprétation (ce qui est un effet essentiellement qualitatif, sur le signifié et ses implications). De plus, la fonction éthique que l'on peut attribuer à la prétérition ${ }^{36}$ assume, de la sorte, une valeur multiple, car l'orateur présente

${ }_{35}$ 'Pleine' de sous-entendus: cf. l'article cité de P. Chiron, p. 114.

${ }^{36}$ Cf. id., ib., p. 122. 
non seulement un éthos de modération, pour sembler se contenir devant le volume de choses qu'il pourrait effectivement dire, mais également un éthos de hauteur, pour ne pas se montrer au même niveau que ceux qu'il accuse, et même de prudence, pour ne pas faire une accusation ouvertement (cf. infra).

A la suite, nous présentons les préceptes du rhéteur et les exemples correspondants.

a) $R h . A l ., 22,1434$ a 17-29 : 'L'ironie (Eipwveía) consiste à dire quelque

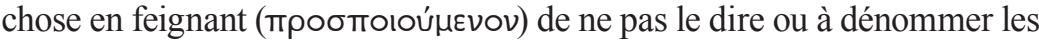
choses par les mots contraires ; la forme qu'elle peut revêtir, dans une brève remise en mémoire des propos tenus, est du genre : 'il n'est aucun besoin, je

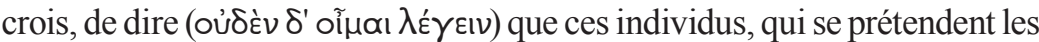
auteurs de tant de bonnes actions, ont manifestement causé d'innombrables torts à la cité, tandis que nous, qu'ils traitent d'ingrats, sommes connus pour les avoir souvent secourus et pour nous abstenir de toute injustice envers autrui'. Voilà donc comment se présente le bref rappel énoncé sous forme

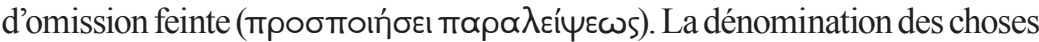
par les mots contraires, maintenant, c'est par exemple : 'Eux, les vertueux, sont connus pour avoir fait beaucoup de mal à leurs alliés, tandis que nous, les méchants, nous le sommes pour leur avoir valu de nombreux avantages'.

[1] Toutes les fois qu'il a traversé mes projets, soit en s'opposant à mes efforts pour faire exempter mes choreutes, soit en vous offrant ses services et en vous poussant à le désigner comme commissaire aux Dionysies, je les passerai sous silence (દ́óow) : je n'ignore pas que, si l'homme persécuté que j'étais alors ressentait à chaque injure autant de colère que pour les plus atroces offences, vous pouvez bien penser - vous qui êtes en dehors de l'affaire - que ces insultes ne valent pas, per elles-mêmes, la peine d'un procès ; mais ce que je vais vous dire va soulever en vous une indignation pereille à la mienne (15).

[2] [Démosthène raconte l'affaire sur l'accusation portée par Midias contre Straton.] (...) (mais laissons encore de côté cette question) ( $\dot{\alpha} \lambda \lambda \dot{\alpha}$ $\mu$ ก́ $\pi \omega$ тоบ̃To) (89).

[3] Le coup monté contre moi dans cette affaire de désertion, le misérable qu'il a soudoyé pour faire cette besogne - je veux dire l'ignoble Euctémon, cette ordure dont il fait ce qu'il veut - je laisserai tout cela

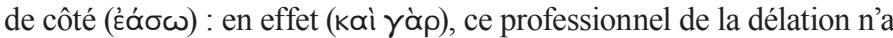
repondu à l'appel préalable (et l'autre n'a acheté cet individu) que pour que chacun pût voir affiché devant les Eponymes : 'Euctémon de Lousia a cité en désertion Démosthène de Paeania.' Je crois qu'il aurait aimé ajouter sur l'affiche, s'il avait pu : 'payé par Midias'. Non, je laisse tout

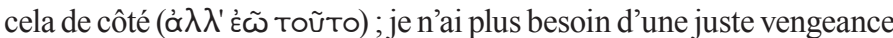


dans une affaire où il s'est frappé d'atimie lui-même, en l'abandonnant ; j'ai satisfaction pleine et entière (103).

[4] Tous les outrages qui m'ont atteint dans ma charge et dans ma personne, toutes les sortes d'attentats et de mauvais traitements auxquels j'ai fini par échapper, vous les conaissez maintenant de ma bouche, Athéniens ; il y a bien des choses que je laisse de côté, parce qu'il n'est

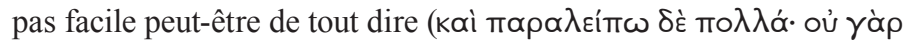

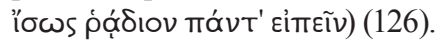

[5] (...) il a commis tant d'injustices à l'égard d'un si grand nombre d'entre vous (...). Je n'arriverais pas à dire devant vous tout ce qu'il a

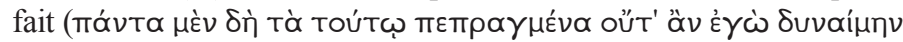

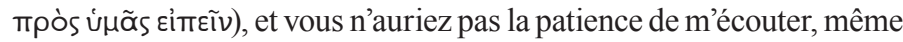
si je disposais maintenant de la quantité d'eau qu'on nous a impartie à nous deux - toute la mienne et toute la sienne en plus ! Non, cela ne

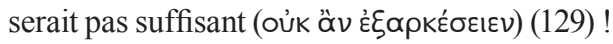

[6] Voilà, Juges, tout le mal qu'il a fait à chacun de ceux qu'il a rencon-

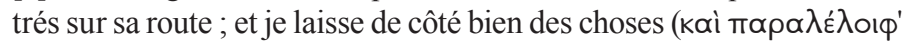

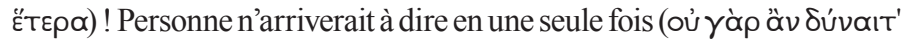

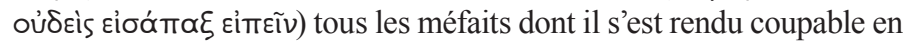
ne cessant d'outrager les autres tout au cours de son existence (131).

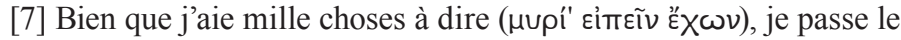

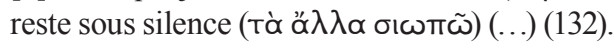

[8] (...) je crois en effet que vous connaissez tous son comportement dans la vie, sa brutalité, son outrecuidance, et j'imagine que depuis un moment il y a des gens qui s'étonnent de ne pas entendre parler de certaines choses qu'ils savent (137).

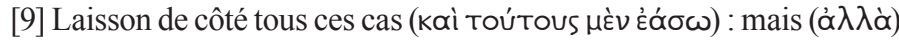
Pyrrhus l'Etéoboutade, certains d'entre vous ont cru devoir le condamner à mort quand il fut dénoncé pour remplir des fonctions de juge tout en étant débiteur envers l'État : frappé par votre tribunal, il fut mis à mort. Pourtant ce salaire, c'était le besoin, et non l'insolence qui lui faisait le rechercher. Je pourrais en citer bien d'autres qui, pour avoir commis des fautes moins graves que Midias, ont été condamnés à mort ou frappés d'indignité civique (182).

b) Rh. Al., 35, 1441 b 20-23 : 'Veille aussi à ne pas dénoncer les actions

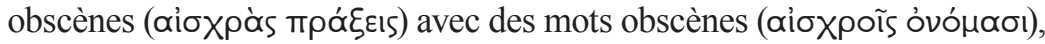

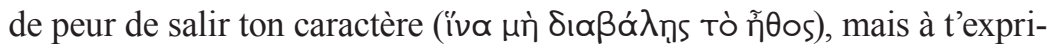
mer sous forme d'énigme ( $\propto$ ivıı $\gamma \mu \alpha T \omega \delta \tilde{\omega}$ ) et à faire comprendre la chose à l'aide de mots qui désignent d'autres choses.'

[1] (...) devant ma soeur ils (sc. Midias et son frère) qui vivait encore 
chez nous - une petite fille à l'époque - ils dirent toutes les horreurs (aỉoxpò kaì toıđũTa) qu'on peut attendre de pareils gens - non ! on ne me fera pas répéter ce qu'ils on dit alors ! - et déveresèrent sur ma

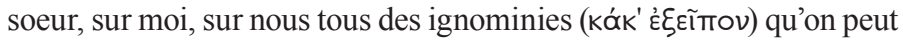

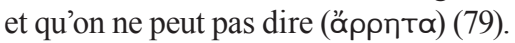

[2] (...) si vous le punissez, on verra en vous des hommes sensés, des braves gens qui ont les coquins en horreur; si vous l'acquittez, on pen-

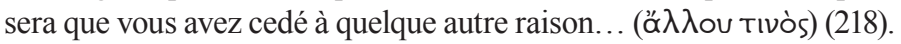

\subsubsection{Réfutation anticipée: la défloration}

Le code est également utilisé - abondamment - dans l'anticipation (procatalepse) et la réfutation des probables arguments de Midias. Démosthène les anticipe de trois modes, essentiellement, en disant ou a) que de tels arguments lui ont été rapportés par une source (cf., p. ex., 24, 2 : á̛níkoo ;

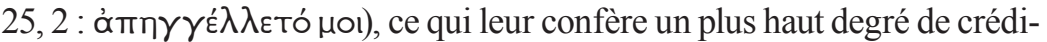

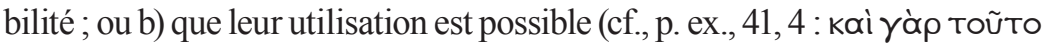

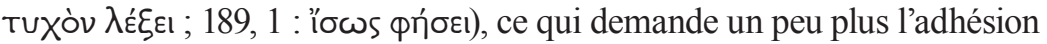
de l'auditoire ; ou c) que lui, Démosthène, 'sait' (ou prétend être sûr, ou considère $^{37}$ ) que Midias fera usage de ces arguments (cf., p. ex., 29, 1 : Oĩ $\delta \alpha$ тoívบv öTı ; 160, 1 : oĨ '́ öTı), ce qui présuppose, de la part de Démosthène, une large connaissance des stratégies de défense possibles pour un accusé tel que Midias, et, de la part de celui-ci - selon ce que Démosthène veut nous faire croire - , la prévisibilité ainsi que la pauvreté de ses stratégies rhétoriques; une telle présupposition de connaissance/méconnaissance de rhétorique - dans la mesure où elle fait partie d'une stratégie argumentative comme celle de la procatalepse - semble être partagée - au moins dans une certaine mesure - par l'auditoire. Nous en traiterons plus avant.

A la suite, nous présentons les préceptes du rhéteur et les cas relevés :

$R h . A l ., 18,1433$ a 31-39 : 'Pour ce qui est des arguments prévisibles des adversaires, je vais indiquer maintenant par des exemples com-

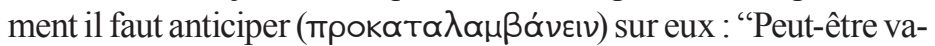

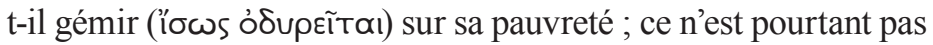
moi mais sa façon de vivre qui en est la cause", ou encore : "J'ap-

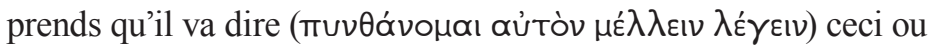

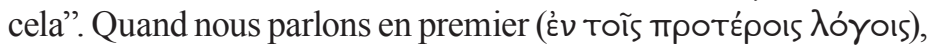
telle est la manière dont il faut anticiper sur les propos prévisibles des adversaires, pour les détruire ou les affaiblir. Car même si les

${ }^{37}$ Cf. L. Spengel (op. cit., p. 179): Demosth. [sc. in Midiam §. 24] ea, quae adversarium ad sese defendendum prolaturum esse putat, refutans haec praemittit... 
points qu'on a dénigrés par avance sont tout à fait solides, ils ne paraîtront pas aussi décisifs ( $\mu \varepsilon \gamma \alpha$ á $\lambda \alpha)$ à ceux qui en auront déjà en-

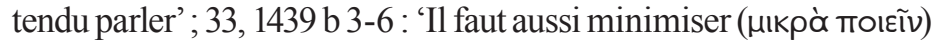
les arguments des adversaires et amplifier ( $\propto u ̛ \xi \varepsilon ı v)$ les tiens, comme tu l'as entendu décrire précédemment dans la partie consacrée aux moyens d'amplification'; e 36, 1443 a 5-7 : 'Après la confirmation, nous placerons ce qui s'oppose aux adversaires en anticipant sur leurs arguments prévisibles.'

\section{Midias :}

a)

[1] Je veux d'abord vous parler des arguments auxquels il recourra

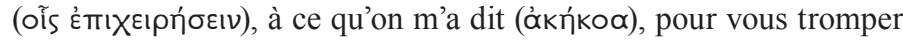

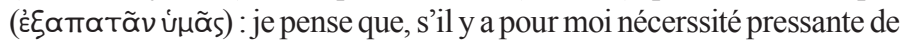
développer ma pensée sur ce point, de votre côté il est fort utile de m'écou-

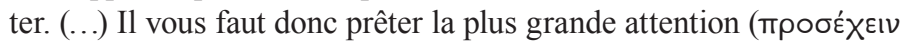

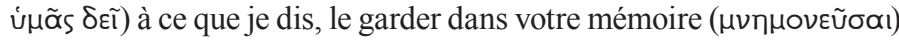
et l'opposer (’̊ $\pi \alpha v \tau \tilde{\alpha} v)$ à chaque argument de mon adversaire (24).

[2] Ce n'est pas un mystère qu'il invoquera d'abord - à juger d'après les conversations personnelles qu'il a eues, m'a-t-on rapporté

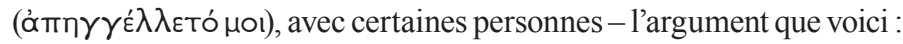
si j'avais réellement enduré ce que je dis, j'aurais dû lui intenter des actions au privé ; (...) mais, non, par Zeus ! lui intenter une action de caractère public, ni proposer une peine afflictive ou pécuniaire. Mais moi, je sais bien une chose, que vous devez aussi savoir : si je ne lui avais pas intenté une plainte préalable, mais une action civile ordinaire, j'aurais à faire face à l'argument inverse (oúvavtíos $\lambda$ ó $^{\prime} \mathrm{S}^{38}$ ), c'est à dire que s'il y avait là-dedans quelque chose de vrai, j'aurais dû déposer une plainte préalable et tirer de lui une vengeance qui fût en rapport avec l'outrage. De fait, le choeur relevait de la cité ; le vêtement était entièrement preparé pour la fête ; et moi, la victime de ses violences, j'étais chorège : qui donc, pour se venger, aurait fait choix d'une autre procédure que celle que la loi a établie contre ceux qui font offense à la fête ? Je sais bien qu'il aurait dit alors tout cela (TaŨT' EŨ oĩ $\delta^{\prime}$ öTI Tớ $v T^{\prime}$

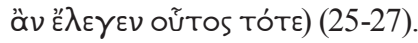

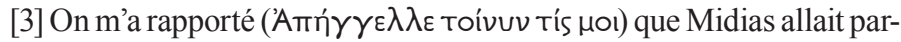
tout, en questionnant tous les gens qui ont pu être victimes de violences, pour collectionner leurs cas, et qu'ils allaient venir vous raconter leurs

\footnotetext{
${ }^{38}$ On note ici la conscience - partagée avec l'auditoire, qui plus est (cf. infra) -, que Démosthène laisse délibérément transparaître, au sujet de la réversibilité des arguments, principe commun à l'argumentation par le Eikós sophistique, ainsi qu'elle est présentée dans la $R h$. Al. (cf.: 7, 1428 b 11 sq.).
} 
histoires (...) : il se figure que, s'il vous montre tant d'autres personnes qui ont subi tant d'affronts scandaleux, vous vous indignerez moins devant ce que j'ai enduré moi-même (36).

b)

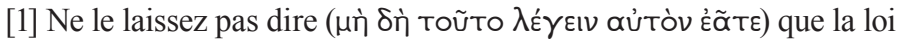
me donne le choix entre des actions privées et une action publique pour outrage ; oui, elle le donne bien ; mais qu'il montre qu'il n'a pas fait ce dont je l'accuse ou, s'il a fait, que ce fut sans offense à la fête (28).

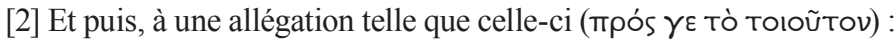
'C'est Démosthène, dit-il, qui a été atteint par l'outrage en question', il y a une réponse juste et fondée sur l'intérêt général, l'intérêt de tous. Non ce n'est pas seulement sur moi, Démosthène, que sa brutalité se déchaînait ce jour-là, mais aussi sur le chorège (...) (31).

[3] Si c'est une chose bien reconnue par vous, il n'y aura plus d'arguments possibles pour lui, plus un seul. Quelle excuse, quel prétexte honnête et convenable pourra apparaître dans son comportement ? La colère par Zeus ? C'est peut être bien ce qu'il dira (kà̀ yà p toũTo TUXòv $\lambda \varepsilon ́ \xi \varepsilon 1)$. Mais non : en face d'actes qu'une impulsion subite, allant plus vite que la raison, a pu faire commettre, on peut dire, même s'ils comportent l'intention d'outrager, qu'ils ont été commis sous l'empire de la colère : au contraire, quand se fait prendre en flagrant délit un homme qui viole les lois de longue date, constamment, à longueur de journées, non seulement cela n'a rien à voir avec la colère, mais encore c'est une préméditation désormais évidente chez un homme qui se livre à ces violences (41).

[4] Peut-être aussi vous trouverez-vous devant un argument de ce genre

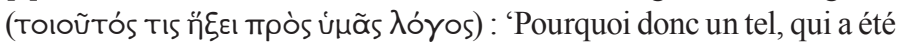
victime de tels ou tels outrages, ne m'en a pas demandé raison?' ou encore 'Pourquoi donc...?', et il désignera sans doute par son nom une autre de ses victimes. Quant aux motifs qui ont détourné chacun d'entre eux de se faire justice lui-même, je suppose que vous les connaissez tous : on n'a pas le temps, on ne veut pas avoir d'histoires (...). Pourtant je crois que cet homme aujoud'hui ne peut pas parler ainsi, mais doit nos apprendre qu'il n'a commis aucune des fautes dont je l'accuse (...) (141-142).

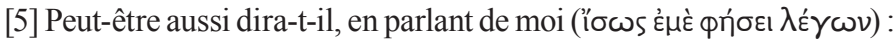
'C'est un orateur, cet homme-là !' Si l'homme qui vous conseille des mesures qu'il croit utiles, sans jamais vous importuner ni jamais forcer votre volonté, est un orateur, je ne saurais me dérober à ce titre, ni le récuser (...). Pourtant, comment est-on fondé à me jeter ce titre à la tête, quand on trouve bon d'employer ces gens-là pour assurer son salut (189) ?

[6] Peut-être bien dira-t-il quelque chose comme ceci (ïows kaì tà

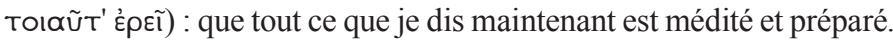


Médité, oui ; je ne saurais le nier, Athéniens, et j'ai mis à l'ouvrage tout le soin dont j'étais capable. Ne serais-je pas un pauvre homme si, après avoir souffert de ces brutalités (et en souffrant encore), je ne m'appliquais pas à ce que je vais vous dire ? (...) (191).

c)

[1] Je sais aussi qu'il fera grand usage de cet autre argument (Oĩ $\alpha$

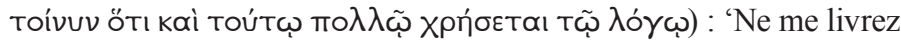
pas à Démosthène! Ne me supprimez pas pour faire plaisir à Démosthène ! Est-ce pour vous une raison de me supprimer, que nous soyons sur le pied de guerre ?' Je sais quil tiendra souvent ce langage (Tò

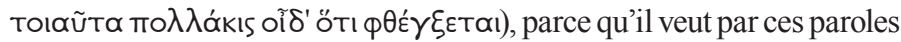
rassembler contre moi je ne sais quelles animosités. Il n'en est pas ainsi (...) ; lorsque quelqu'un a été victime d'une injustice, vous ne suivez pas davantage ses suggestions pour châtier le coupable. Au contraire, vous avez établi les lois antérieurement aux délits, sans savoir qui commettra l'injustice et qui en sera la victime (29-30).

[2] 'Oui, mais par Zeus, il nous a fait don d'une trière.' Je sais qu'il n'aura

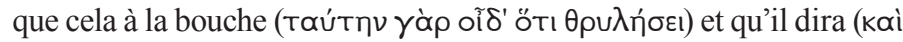
$\phi \eta ́(\sigma)$ : : 'Je vous ai fait, moi, don d'une trière'. Faites donc comme ceci, Athéniens : si c'est une noble ambition qui l'a poussé à vous l'offrir, ayez pour lui la reconnaissance qu'un tel acte mérite, mais ne lui accordez point le droit de vous outrager (...). Mais si on vous démontre que c'est pour lâcheté et par covardise qu'il a agi ainsi, ne soyez pas ses dupes (160).

[3] Même si son activité dans sa liturgie avait été réellement telle qu'il

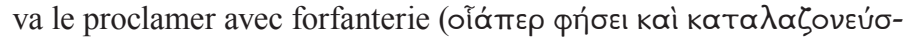
$\varepsilon \tau \alpha$ I) devant vous dans peu de temps, et non telle que je vais le montrer

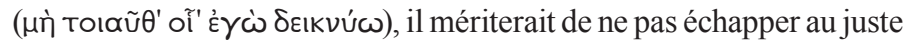
châtiment de ses violences en invoquant ses liturgies (169).

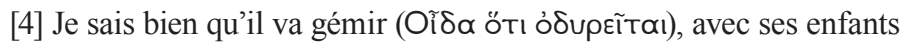
à ses côtés, et qu'il prononcera force paroles pleines d'humilité (kaì

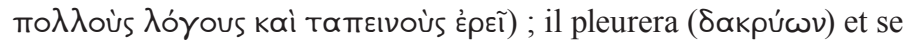
fera le plus pitoyable qu'il pourra. (...) (186).

[5] Je pense qu'il n'hésitera pas non plus à accuser le peuple et l'assemblée et qu'il répétera ce qu'il a osé dire au moment de la plainte : il n'y avait dans l'Assemblée que des gens qui étaient restés dans leurs foyers alors qu'ils auraient dû partir à la guerre (...) (193).

[6] Il faut à votre tour, Athéniens, quand il viendra geindre, pleurer,

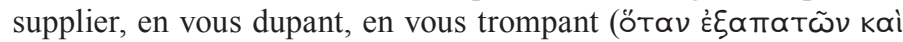

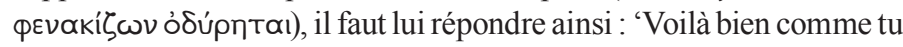
es, Midias ! Tu es violent, tu ne peux laisser tes bras le long de ton corps. Après cela, t'ettones-tu si le misérable que tu es doit finir misérablement? Alors tu crois que nous recevrons les coups, et que tu les donne- 
ras? que nous t'acquitterons, et que tu continueras à agir ainsi ?' (204).

Voir, aussi, en particulier :

Rh. Al., 4, 1427 a 14-20 : 'Dis aussi que "si l'on prête l'oreille à celui qui se défend ainsi (sc. en disant qu'il a commis une faute ou, après avoir bien médité l'entreprise, qu'il a manqué de chance), on multipliera le nombre de ceux qui commettent des délits délibérément

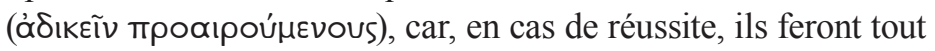
ce qui leur plaira, et, en cas d'échec, ils éviteront le châtiment sous prétexte de malchance". Les accusateurs doivent empêcher le pardon à partir de ce genre d'argument et (...) prouver par les moyens

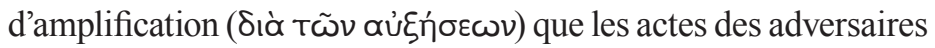

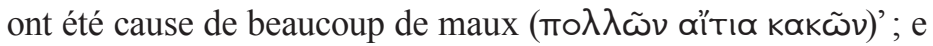
36,1443 a $41-1443$ b 24 : '(...) si, tout en admettant les faits, les adversaires prétendent au pardon, voici comment il faut leur retirer ce moyen de défense. Il faut d'abord dire que l'action ne laissait pas d'être vicieuse, et qu'un tel aveu de faute est ce que l'on fait quand on est découvert, si bien que "si vous lui pardonnez, vous dispen-

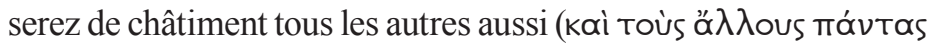

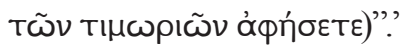

\section{Midias :}

[1] On m’a rapporté que Midias allait partout, en questionnant tous les gens qui ont pu être victimes de violences, pour collectionner leurs cas, et qu'ils allaient venir vous raconter leurs histoires : par exemple, celle du proèdre qui, dit-on, fut sous vos yeux frappé naguère par Polyzélos, ou celle du thesmothète qui fut frappé récemment en prêtant main-forte à la joueuse de flûte, et d'autres du même style (kai toıoútous Tivás) : il se figure que, s'il vous montre tant d'autres personnes (mo $\lambda \lambda$ oùs ÉTÉpous) qui ont subi tant d'affronts scandaleux, vous vous indignerez moins devant ce que j'ai enduré moi-même. Selon moi, vous auriez raison, Athéniens, d'agir en sens inverse, si vous vous souciez de l'intérêt suprême de la communauté. Qui ignore parmi vous que l'impunité des coupables fait se multiplier des actes de ce genre, et qu'infliger à tout individu que l'on prend la peine qui convient est le seul moyen d'empêcher que personne ne soit, dans la suite, victime de violences ? S'il est de votre intérêt de détourner les autres de pareilles façons, vous avez à châtier cet homme pour ses fautes (...); si vous voulez, au contraire, exciter son audace et celles des autres, vous n'avez qu'à le laisser impuni (36-37).

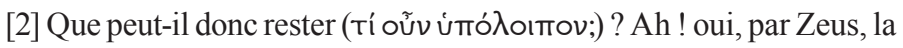
pitié ! Il produira ses enfants auprès de lui ; il pleurera et se servira d'eux 
pour se tirer d'affaire : c'est tout ce qui lui reste (ToũTo yà ! Vous savez pourtant qu'il convient de donner sa pitié à ceux qui, injustement traités, ne pourront pas supporter cet affront, non aux gens qui expient justement une conduite scandaleuse. Qui donc se sentirait fondé à avoir pitié de lui, en voyant les enfants de l'autre (sc. Straton), dont il (sc. Midias) n'a pas eu pitié - ces enfants qui, en plus de tous leurs malheurs, se voient sans appui, du fait de la triste situation de leur père? Quel est l'homme qui cessera d'outrager autrui (...), si vous avez pitié de Midias comme d'une victime, et si, devant un homme pauvre qui, sans avoir rien fait de mal, est tombé sous le coup des plus grands malheurs par la faute de Midias, vous ne vous associez même pas à l'indignation de Straton (99-100)?

\subsubsection{Exploitation des inductions spontanées}

Le code est également appliqué dans ce que l'on appelle l'exploitation des inductions spontanées (faites à partir du vraisemblable); dit le rhéteur :

Le vraisemblable (Eikós) est ce dont, quand on le dit, les auditeurs ont

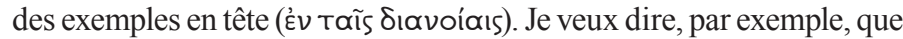
si l'on affirmait désirer que sa patrie soit grande, ses proches heureux, ses ennemis malheureux et ainsi de suite, eh bien $<$ de telles affirmations $>$, pour le dire en un mot, paraitraient vraisemblables. Car chacun

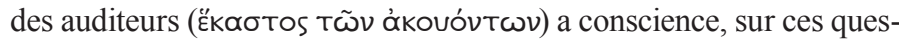
tions et les questions de même nature, d'éprouver personnellement de

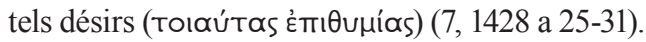

Or, Démosthène cherche à obtenir l'adhésion de l'auditoire à sa cause fondée sur le propre caractère vraisemblable qu'elle offre, car, intenter un procès à Midias, est chose que, - selon lui - n'importe qui, parmi ceux qui l'écoutent, ferait, s’il était dans les mêmes conditions.

A ce sujet, voir, avant :

(...) nous devons toujours, dans nos discours, nous préocuper de savoir si nous rencontrerons chez nos auditeurs une connivence (бUveıاठótas)

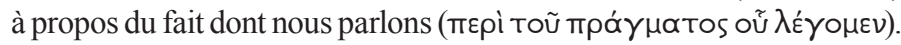
Car dans ce cas, il est vraisemblable qu'ils y accorderont le plus grand

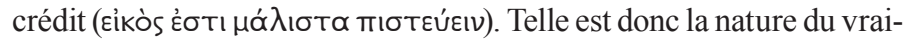
semblable. Nous le divisons en trois classes. La première consiste à mettre à contribution, $<$ dans $>$ nos discours, que ce soit dans l'accusation ou la défense, le passions qui escortent la nature humaine (Tà

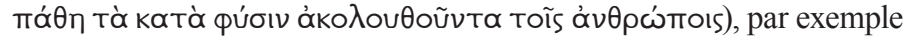
si certains se trouvent avoir éprouvé des sentiments de mépris ou de crainte envers quelqu'un, quand bien même ils ont souvent commis 
l'acte en question, ou encore s'ils ont ressenti de la joie ou du chagrin, s'ils ont des désirs ou cessé d'en avoir ou [s'ils sont riches] s'ils ont éprouvé toute autre passion du même genre, par l'âme, par le corps où [sic] n'importe lequel des sens dont nous partageons l'expérience. Car ces passions et les passions semblables, étant passions communes à la

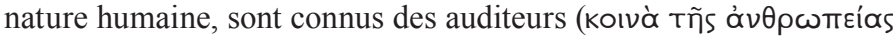

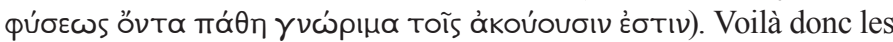
passions naturelles que les hommes ont coutume d'éprouver et qu'il faut, disons-nous, mettre à contribution dans nos discours. La deuxième

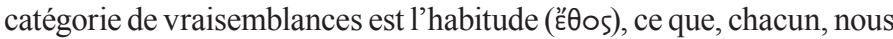
avons coutume de faire. La troisième est l'intérêt ; car c'est souvent à cause de lui que, quitte à faire violence à notre nature et à notre caractère, nous nous déterminons à agir. (Rh. Al., 7, 1428 a 31 - 1428 b 10)

\section{Et dans le C. Midias :}

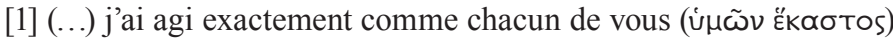

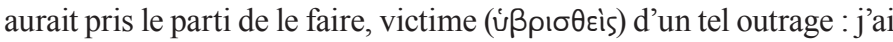
intenté une plainte pour offense à la fête (...) (1).

[2] (...) ce que je vais vous dire va soulever en vous une indignation

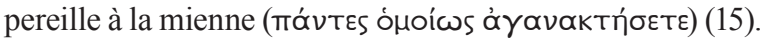

[3] (...) à propos de tout ce vous m'entendez dire, écoutez-moi en ayant

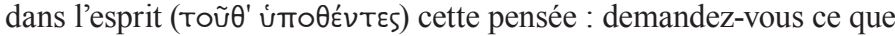

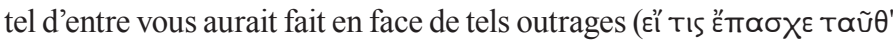
ú $\mu \tilde{\omega} v)$, et quel ressentiment il en aurait gardé, pour son compte, à l'égard de leur auteur. Quant à moi ('̇y les outrages que j’ai essuyés au cours de ma liturgie (...)(108).

D'autre part, l'orateur s'attache à montrer que Midias, non seulement par l'attitude outrageante qu'il a prise, (cf. supra), mais aussi par le caractère habituel, est un homme qui en tout est dissemblable du commun du peuple. Le raisonnement semble être : moi, Démosthène, je suis l'un de vous ; en intentant un procès à Midias, nous attaquons un homme qui ne respecte pas notre communauté : la stratégie est inclusive par rapport à Démosthène, et exclusive, ou ablative, par rapport à Midias :

[1] Quel homme en effet, après un vote qui le frappait pour impiété et outrage à la fête (...), ne se serait pas fait petit sur le moment et n'aurait pas feint la modération, du moins jusqu'à la fin du procès, si ce n'est

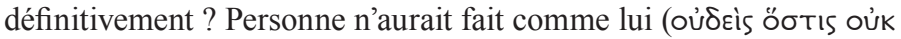

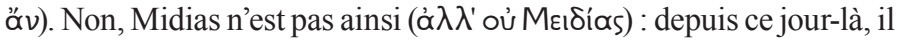
parle, il injurie, il vocifère (199-200).

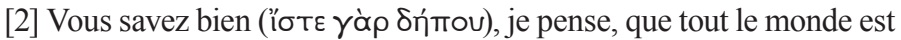




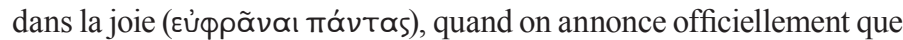
nos affaires marchent comme il faut, ou à toute nouvelle de ce genre :

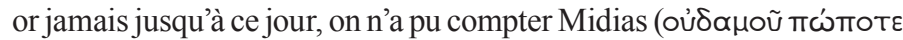

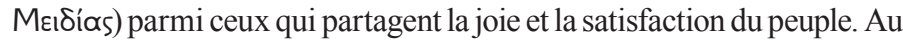
contraire, apporte-t-on une nouvelle que personne - sauf lui - ne voudrait entendre ? Midias est le premier à se lever : (...) il prend la parole et vous dit : 'Voilà bien comme vous êtes, Athéniens! Vous ne voulez pas aller à la guerre, et vous ne voulez pas payer vos impôts. Après cela, vous étonnez-vous si vos affaires sont mal en point? (...).' Telles sont ses paroles outrageantes : les circonstances découvrent l'amertume ( $\pi$ ı́ṕav) et la malveillance (kakóvoı $v$ ) profondes que vous lui inspi-

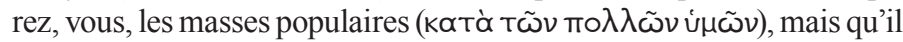
dissimule au fond de lui-même (202-204).

L'utilisation du eikós sophistique se réalise également dans le jeu sur les préjugés. Le rhéteur prescrit : ' $<\mathrm{si}>$ celui qui tu accuses est jeune, ce que font les gens de cet âge, dis qu'il l'a fait ; en raison de la ressemblance, on accordera crédit aussi aux accusations portées contre lui (7, 1428 b 26-29)'.

Dans le C. Midias, on voit :

[1] Victime de ces violences, harcelé de la façon que je suis en train de vous exposer, moi qui pourtant ne compte pas parmi les gens les plus démunis d'appuis et de ressources, je ne sais pas ce que je dois faire, Athéniens. Si j’ose maintenant dire un mot à ce sujet, non, Athéniens ! en face de riches (mpòs toùs $\pi \lambda$ ovoíous) nous n’avons pas, nous les pauvres

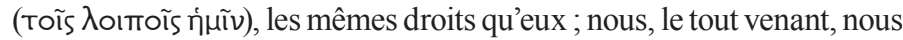
ne sommes pas à égalité avec eux, non! On accorde à ces gens-là tous les délais qu'ils désirent, pour se soumettre à la justice : quand ils arrivent devant vous, tous leurs délits sont refroidis et éventés, tandis que chacun de nous, s'il a un ennui, est jugé quand le délit est encore tout chaud. Ces gens-là (Toútoıs) ont à leur disposition des témoins, des gens qui parlent en leur faveur et qui sont tout prêts à marcher contre nous : vous voyez même que certains m'ont refusé de témoigner de la vérité (111-112).

[2] (...) vous devez tous être également animés du même courroux (ãoıv ónoíws ópyıotéov), en considérant que les plus pauvres d'entre vous et les plus dépourvus d'appuis sont les plus exposés à l'injustice, tandis que, s'il s'agit d'outrager les autres et d'échapper au châtiment de leurs actes, ou encore de payer des gens pour parer le coup en créant des ennuis à leurs adversaires, ah ! ils ne sont pas loin, ces sales gens (oi

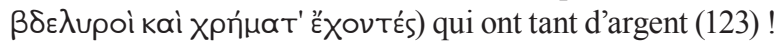

[3] (...) certaines gens sont venus me trouver, Juges, qui sont ses (sc. de Midias) amis : ils me conseillaient de renoncer au présent procès et de laisser tomber les poursuites. (...) ils ont rencontré l'argument 


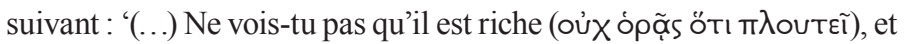
qu’il parlera de ses triérarchies, de ses liturgies ? Prends-garde (бко́тє।

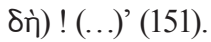

[4] Un homme qui trouve déshonorant de vous craindre et juge crâne de ne point se soucier de vous, Athéniens, ne convient-il pas dis fois de le punir de mort? Il pense que vous ne saurez que faire avec lui : riche, audacieux, sûr de lui, ayant le verbe haut, violent, cynique, comment vous saisirez-vous de lui, si vous vous laissez aujourd'hui duper par lui (201)?

\subsection{Surdétermination et retournement ${ }^{39} d u$ code}

En plus de la simple application du code rhétorique, l'orateur assume également que - pour sa part - il l'utilise (d'où la surdétermination du code), mais à sa manière (car 'il cherche à dire ce qui est juste' : cf. 192, 3-4 :

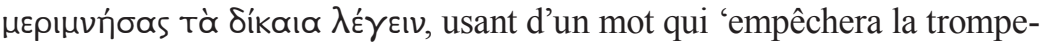

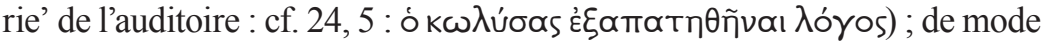
complémentaire, il soutient que - de la part de son adversaire - une telle utilisation se produira également et sera pernicieuse (d'où le retournement), car

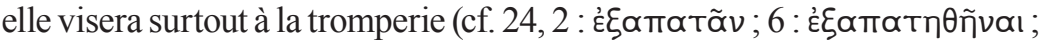

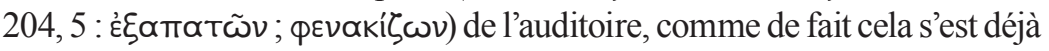
produit, Midias ne s'en étant servi que pour dire du mal de tout le monde

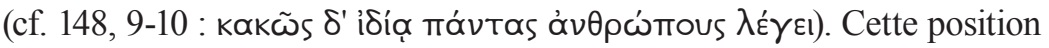
se fonde sur la reconnaissance de la 'perversité éventuelle" ${ }^{40}$ du code rhétorique : Démosthène, en réfutant - en une procatalepse - l'accusation que lui, Démosthène, est un orateur (accusation qui présuppose, sur ce point, la possibilité d'utiliser le terme 'orateur' comme un élément déclencheur d'inductions négatives de la part de l'auditoire, à partir de ses préjugés), en réfutant, enfin, une telle 'accusation', présente, en ce qui concerne le fait qu'il soit orateur, une définition positive (qui comporte d'ailleurs non seulement

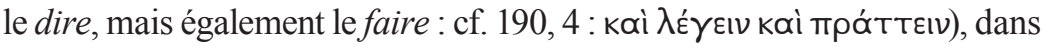
laquelle il s'inclut lui-même (et de laquelle il exclut les orateurs qui sont aux côtés de Midias), et une définition négative (qui comporte l'idée d'enrichis-

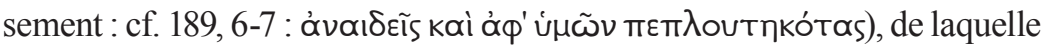
il s'exclut, et dans laquelle, enfin, s'incluent ceux qui soutiennent Midias.

Quant à ce que le rhéteur établit, lisons :

Rh. Al., 36, 1444 a 28-34 : 'Si les adversaires prétendent que nous apprenons l'art de parler et que nous faisons des exercices ( $\lambda \varepsilon ́ \gamma \varepsilon ı \nu$

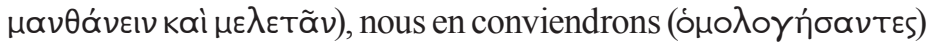

\footnotetext{
${ }^{39}$ Sur ces termes, voir l'article cité de P. Chiron, p. 127-133.

${ }^{40}$ Cf. id., ib., p. 131.
} 
en disant: 'nous les apprentis-orateurs, comme tu dis, nous ne sommes pas procéduriers, mais toi, qui ne sais pas parler, tu es pris maintenant contre nous, et déjà dans le passé, en flagrant délit de délation'. Il apparaîtra alors de l'intérêt des concitoyens que lui aussi apprenne la rhétorique, car il ne serait pas alors un si méchant délateur.'

Et confrontons-le à ce que nous trouvons dans la Midienne :

[1] Peut-être aussi dira-t-il, en parlant de moi : 'C'est un orateur, cet

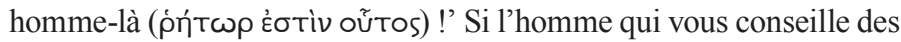
mesures qu'il croit utiles, sans jamais vous importuner ni jamais forcer

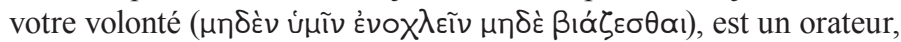
je ne saurais me dérober à ce titre, ni le récuser ; mais si l'orateur est comme certaines personnes qui parlent ici (et que nous voyons vous et moi), des hommes qui sont impudemment enrichis à vos dépens

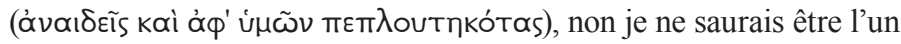
d'eux (...). De plus, il n'y a pas un seul de ces orateurs qui combatte à mes côtés. Et en cela je ne fais de reproches à personne : jusqu'à ce jour je n'ai jamais dit devant vous rien qui pût les favoriser; j'ai simplement pris à part moi le parti de dire et de faire tout ce que je crois être de votre

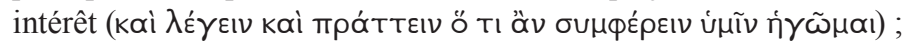
mais, pour lui, vous verrez dans un instant tous les orateurs venir se ranger à ses côtés, l'un après l'autre. Pourtant, comment est-on fondé à me jeter ce titre à la tête, quand on trouve bon d'employer ces gens-là pour assurer son salut (189-190)?

[2] Je veux d'abord vous parler des arguments auxquels il recourra (...) pour vous tromper ( $\dot{\xi} \xi \alpha \pi \alpha \tau \tilde{\alpha} \nu$ ú $\mu \tilde{\alpha} \varsigma)$ : je pense que, s'il y a pour moi nécessité pressante de développer ma pensée sur ce point, de votre côté il est fort utile de m'écouter. Pour quoi cela ? Parce que la parole qui

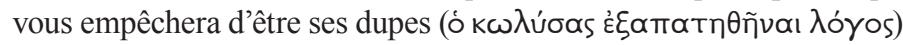
vous fera rendre une sentence juste et conforme à votre serment. Il vous faut donc prêter la plus grande attention à ce que je dis, le garder dans votre mémoire et l'opposer à chaque argument de mon adversaire (24). [3] (...) n'allez pas croire, Juges, que la morale, la loi divine ou la piété vous permettent (...) de juger digne de votre indulgence, de votre bonté humaine ou de quelque autre faveur, ce coquin, cette brute, ce violent que vous tenez, cet homme de rien, fils de rien. Pourquoi agiriez-vous ainsi ? En considérations de ses campagnes ? Mais, en tant que soldat, il ne vaut rien ; encore moins pour commander aux autres. En considération de son éloquence ( $\left.\tau \tilde{\omega} v \lambda{ }^{\prime} \gamma \omega \nu\right)$ ? Mais jusqu’à présent il n'a jamais

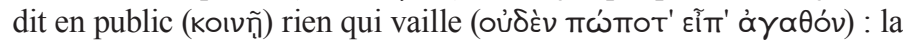
parole ne lui sert, dans le public (ißíá), qu'à déblatérer contre tout le

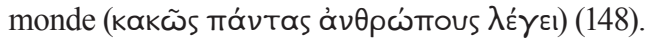


[4] Ne laissez pas cet homme parler dans ce sens, et ne croyez pas, s'il

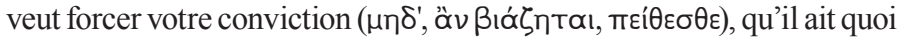
que ce soit de juste dans ce qu'il dit (40).

[5] Je sais bien qu'il va gémir, avec ses enfants à ses côtés, et qu'il prononcera force paroles pleines d'humilité ; il pleurera et se fera le plus pitoyable qu'il pourra. Il mérite d'autant plus (Toбoútœ), Athéniens, d'attirer votre haine qu'il (ö $\sigma \omega)$ se fera aujourd'hui plus humble (...) (186).

[6] Il ne faut donc pas l'écouter, ni accorder aux circonstances présentes,

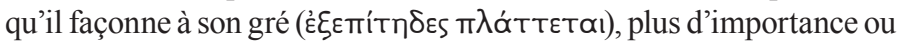
de crédit qu'à tout un passé que vous connaissez bien (...) (187).

[7] Il faut à votre tour, Athéniens, quand il viendra geindre, pleurer,

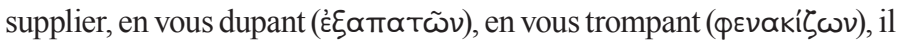
faut lui répondre ainsi : 'Voilà bien comme tu es, Midias ! Tu es violent, tu ne peux laisser tes bras le long de ton corps. Après cela, t'ettones-tu si le misérable que tu es doit finir misérablement ? (...)' (204).

[8] (...) ah ! qu'il n'existe jamais dans une démocratie un homme dont

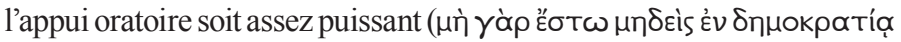

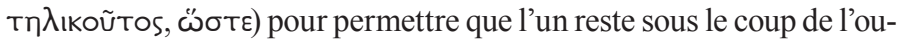
trage, tandis que l'autre reste impuni (207)!

De surcroît, Démosthène cherche aussi à se défendre de l'accusation d'avoir préparé à l'avance tout ce qu'il dit, recourant pour ce faire à un ingénieux argument ; confrontons, ici, le précepte du rhéteur ${ }^{41}$ et le passage auquel nous faisons référence :

(...) si on nous critique en disant que nous prononçons des discours

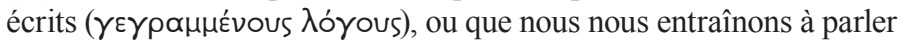
( $\lambda \varepsilon ́ \gamma \varepsilon \mid \nu \mu \varepsilon \lambda \varepsilon \tau \tilde{\omega} \mu \varepsilon v)$, ou bien que nous faisons le synégore contre rétribution, il faut, contre de telles imputations, marcher à l'attaque en

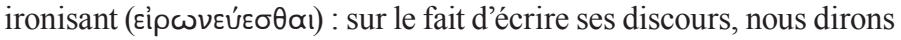
que la loi n'interdit ni à toi-même de dire un texte écrit, ni à l'adversaire de parler sans avoir rédigé, car la loi interdit de faire telle ou telle chose, mais laisse entière la liberté de parler comme on veut. Il faut dire aussi que 'mon adversaire considère que $<j$ ' $>$ ai de si grands torts $(<\mu \varepsilon>$

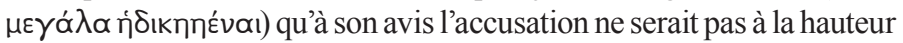
si je n'écrivais pas ma plaidoirie et ne passais pas beaucoup de temps

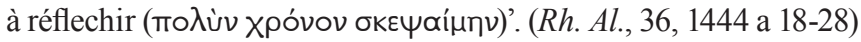

${ }^{41} \mathrm{Cf}$., à ce sujet, le commentaire de L. Spengel (op. cit., p. 265) : tam apta sunt et conveniunt quae in Midiana confutatione $\$ .191-2$ (..) leguntur, ut inde (sc. 36, 80, $11=R h$. Al.,

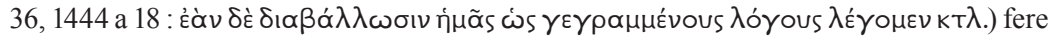
praeceptum sumptum esse credas. 


\section{Midias :}

Peu-être bien dira-t-il quelque chose comme ceci : que tout ce que je dis

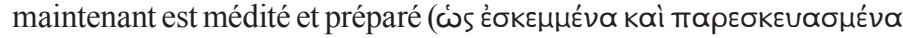

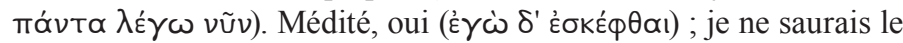
nier, Athéniens, et j'ai mis à l'ouvrage tout le soin dont j'étais capable ( $\mu \varepsilon \mu \varepsilon \lambda \varepsilon T \eta \kappa \varepsilon ́ v \propto l)$. Ne serais-je pas un pauvre homme si, après avoir souffert de ces brutalités (Toı $\alpha \tilde{T} \alpha \pi \alpha \theta \omega \dot{v}$ ) (et en souffrant encore), je ne m'appliquais pas à ce que je vais vous dire ? Pourtant, je vous le dis, l'au-

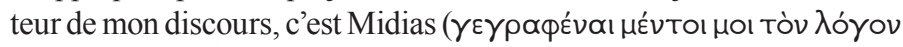

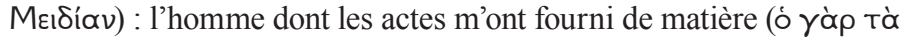

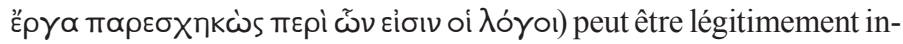
criminé de tout ce soin, non celui qui s'applique à faire parler la justice

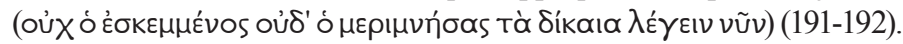

\subsubsection{La compétence rhétorique vis-à-vis du public}

La connivence entre l'orateur et le public peut se produire à un niveau simple: parexemple, celui de la connaissance du passé et du caractère de Midias:

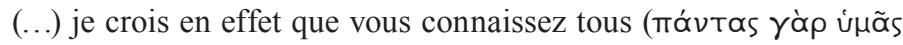

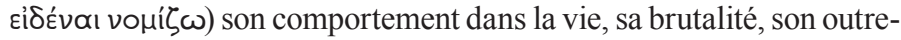
cuidance, et j'imagine que depuis un moment il y a des gens qui s'éton-

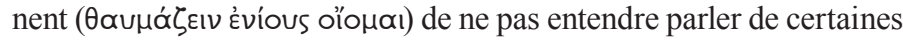
choses qu'ils savent $(137)^{42}$.

Mais il semble y avoir également - pour le moins dans une certaine limite, celle des marques présentes dans le texte - une connivence avec le public au niveau de la compétence rhétorique, autrement dit : Démosthène démontre avoir conscience que l'auditoire, en ce qui concerne les moyens rhétoriques, a suffisamment de connaissances pour se douter qu'en tant qu'orateur, il peut se montrer artificieux :

On ne peut pas dire non plus que je profite du fait que le scandale est sans précédent pour grossir l'affaire et en faire quelque chose d'épou-

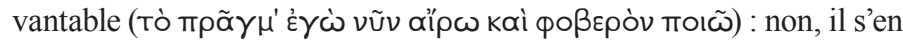
faut bien, et de beaucoup (71) ;

tout comme il suppose que l'auditoire a connaissance des motifs - vraisemblables - pour lesquels d'autres victimes de Midias ne l'ont pas poursuivi devant la justice :

Peut-être aussi vous trouverez-vous devant un argument de ce genre :

${ }^{42}$ Cf. aussi : $1 ; 77 ; 132 ; 187 ; 206$. 
'Pourquoi donc un tel, qui a été victime de tels ou tels outrages, ne m'en a pas demandé raison ?' ou encore 'Pourquoi donc... ?', et il désignera sans doute par son nom une autre de ses victimes. Quant aux motifs qui ont détourné chacun d'entre eux de se faire justice lui-même, je suppose

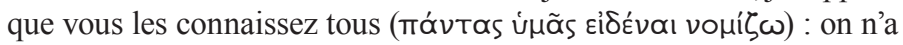
pas le temps, on ne veut pas avoir d'histoires (...) (141);

et la connaissance, enfin, de ceux qui, parmi les présents, font un usage pernicieux de la rhétorique :

(...) si l'orateur est comme certaines personnes qui parlent ici (et que

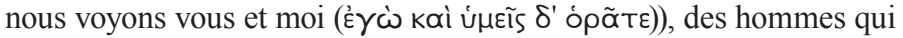
sont impudemment enrichis à vos dépens, non je ne saurais être l'un d'eux (...) (189).

Notre examen de la Midienne reste partiel. En effet, d'importants aspects ont été écartés, telle l'étude de l'amplification stylistique, parmi les ressources de l'effet de masse dans la modification de la perspective, et l'étude de ce qui est appelé 'l'omission simple' comme l'un des procédés sophistiques dans l'application du code : en fait, quant au premier, les limites de ce travail ne nous ont pas permis de l'aborder; quant au second, nous dépendrions, pour la détection de ce procédé, d'un ensemble d'informations dont nous ne disposons pas ${ }^{43}$. Nous n'avons pas, par ailleurs, réalisé d'examen particulier de la Tó́łıs, dans les cas présentés.

Cependant, à partir de la confrontation de ces cas - dont le nombre a cherché à être exhaustif - avec les préceptes extraits de la $\mathrm{Rh}$. Al., confrontation qui en somme a cherché à mettre en évidence une confluence à la fois terminologique et méthodologique, nous croyons pouvoir conclure que le code rhétorique présent dans la $R h$. $A l$., où il est en état de préceptes, apparaît également - pour le moins dans les limites de ce que nous avons examiné ici, et cette réserve est importante - en l'état de discours, en l'état de pratique, dans le cas de la Midienne.

Dans la mesure où il serait possible d'en dire autant au sujet d'autres discours, se confirme, d'une part, l'applicabilité du Traité à la lecture des orateurs de la même période, et, d'autre part,--en raison de la tradition que la $R h$. Al. implique - s'ouvre une voie importante pour la connaissance de la rhétorique du IV $\mathrm{V}^{\mathrm{e}}$ siècle telle qu'elle est établie par des manuels aujourd'hui disparus.

${ }^{43}$ Quand même, nous renvoyons le lecteur à, p. ex., C. Midias, 58, 11 (cf. supra, n. 30) et 104, 5, ainsi qu'aux respectives notes de J. Humbert: p. 182 e 185. 


\section{Appendice}

Nous présentons, à la suite, quatre cas de proximité entre le rhéteur et l'orateur qui, bien qu'ils échappent au schéma général de notre travail, semblent aussi contribuer à en corroborer la conclusion :

1) Rh. Al., 1, 1422 a $28-38$ :

Ce qu'est le semblable au juste, en voici un exemple : (...) 'Comme il est juste d'accorder des bienfaits en retour à ceux qui nous ont fait du bien, de même il est juste de ne pas nuire à ceux qui ne nous ont fait aucun mal'. (...) À partir des contraires, < voici comment> il faut rendre le juste [l'exemple] évident : 'Car de même qu'il est juste de châtier ceux

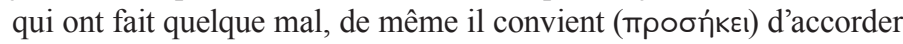
des bienfaits en retour à ses bienfaiteurs'.

\section{Midias :}

Je crois que tous les hommes trouvent légitime de se constituer, dans la vie, comme un fonds par cotisation (Épavov) qui est à l'image de leurs actes : par exemple, suis-je quelqu'un de modéré, de compatissant, de

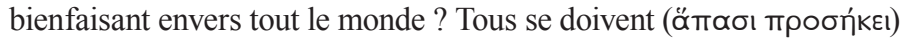
d'apporter à un homme de la sorte la même cotisation, si l'occasion ou la nécessité s'en présente. Cet autre est-il brutal, impitoyable envers tous ? Croit-il ne pas avoir à faire à des êtres humains? Il est juste qu'à cet homme-là chacun réserve une contribution semblable. Hé bien ! toi qui t'es assuré une créance sur un fonds de ce genre, il est légitime que tu la touches (101)!

\section{2) Rh. Al., 2, 1423 a $32-39$ :}

Si nous disons qu'il faut les (sc. les cultes) conserver en l'état, nous trouverons des resources, tout d'abord, dans le juste, en disant que 'il est partout injuste de transgresser les coutumes ancestrales'; et que 'les oracles sont unanimes à prescrire aux hommes d'accomplir les sacrifices à la manière ancestrale', et qu' $i l$ faut le plus possible que perdurent les pratiques religieuses des premiers fondateurs des cités, qui ont bâti les temples aux dieux'.

\section{Midias :}

Vous savez, je pense, que tous ces chants, tous ces choeurs sont um hommage rendu au Dieu : ce n'est pas seulement suivre en cela la tradition des Dionysies, c'est obéir à tous les oracles, aussi bien de Delphes que de Dodone, qui enjoignent à notre cité - vous pouvez le constater - de former des choeurs suivant la tradition de nos pères, de dresser des 
autels à Apollon Agyeus et d'y faire fumer des sacrifices, et de porter des couronnes. (Dans la suite, on fait la lecture des oracles de Dodone) (54) (...) Que faut-il penser de tout cela ? Que ces oracles (...) vous enjoignent (...) de former des choeurs et de porter des couronnes selon les traditions de nos pères (51-54).

3) [Cf. L. Spengel, op. cit., p. 182] Rh. Al., 19, 1433 b 18-28 :

Parmi elles (sc. les requêtes), les unes sont injustes, les autres justes. Il est juste de demander l'attention à ce qu'on dit et une écoute bienveillante, il est juste aussi de demander qu'on nous secoure dans le respect des lois, qu'on ne vote rien qui soit contraire aux lois et qu'on pardonne à la malchance. ${ }^{\dagger}$ Mais si la requête est en contradiction avec les lois, elle est injuste ; sinon, elle est juste. ${ }^{\dagger}$ Voilà donc ce que sont les requêtes ; nous avons exposé les différences qui les séparent afin que, sachant ce qui est juste et ce qui ne l'est pas, nous nous en servions opportunément et que, si nos adversaires adressent aux jurés une requête injuste, cela ne nous échappe pas.

\section{Midias :}

[1] Si je devais le (sc. Midias) poursuivre, pour motion illégale ( $\pi \propto \rho \vee \nu{ }^{\mu} \mu \omega \nu$ ), ou pour ambassade infidèle, ou pour tout autre motif semblable, je ne me croirais pas fondé à vous adresser une requête, estimant qu'en la matière l'accusateur n'a qu'à prouver son dire, tandis que l'accusé peut aussi faire appel à la pitié (...) (5).

[2] Non! ces gens-là (sc. Philippide, Mnésarchidès, Diotime d'Euônymée et d'autres, qui vont demander d'acquitter Midias) ne sont pas fondés à vous présenter cette requête : 'Juges, ne suivez pas les lois en jugeant ; ne prêtez pas assistance à un homme odieusement traité ; ne soyez pas fidèles à votre serment ; accordez-nous cette faveur !'. Voilà ce qu'ils vous demanderont en vous demandant pour lui cette faveur, même s'ils n'emploient pas ces termes (211).

[3] Si ces gens-là (sc. les amis de Midias), qui ont de la fortune, ne peuvent pas sacrifier un peu d'argent, en quel sens serait-il honorable pour vous de sacrifier votre serment? Beaucoup de riches qui se tiennent, Athéniens, et se croient gens d'importance parce qu'ils ont de la fortune vont venir vous implorer de leur accorder cette requête. Ah! ne me sacrifiez à aucun d'entre eux, Athéniens ! Mais, de même qu'ils feront tous preuve d'activité pour défendre Midias et leurs intérêts personnels, faites preuve d'activité, vous aussi, en défendant la cause des lois et celle d'un homme qui a mis en vous tout son recours (...) (212-213). 
4) [Cf. L. Spengel, op. cit., p. 227] Rh. Al., 34, 1440 a 25-29 : '(...) tandis que, dans les discours d'exhortation, il faut faire ressortir ou bien que les bénéficiaires du secours proposé éprouvent de l'amitié pour ce à qui nous donnons ce conseil, ou bien que ces derniers doivent [avoir] de la reconnaissance envers ceux qui demandant de l'aide, si nous nous opposons au secours, nous montrerons que ceux qui le demandent méritent la colère,

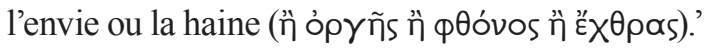

\section{Midias :}

$\mathrm{Tu}$ (sc. Midias) aurais découvert un puissant moyen d'action - ou plutôt un puissant artifice - si tu pouvais, en si peu de temps, t'assurer de deux sentiments aussi opposés que possibles : la haine pour la vie que tu mènes, et la pitié pour tes larmes trompeuses. Rien ne te donne droit au moindre mouvement de pitié, mais tout au contraire te désigne à la

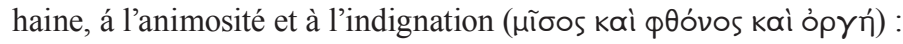
c'est cela que méritent tes actes (196).

Título. O Contra Mídias à luz do código retórico presente na Retórica a Alexandre Resumo. A Retórica a Alexandre ( $R h . A l$.), normalmente atribuída ao sofista Anaxímenes de Lâmpsaco (c. 380-320 a.C.), pode ser um caminho para o conhecimento do que se encontrava nos manuais de retórica em uso na primeira metade do século IV a.C. e, a partir daí, para um conhecimento mais preciso do código retórico praticado pelos oradores áticos. O objetivo deste estudo é demonstrar que o código retórico presente na $R h$. Al., na qual se acha no estado de preceitos, aparece igualmente no estado de discurso, isto é, no estado de prática, no caso do Contra Mídias de Demóstenes.

Palavras-chave. Retórica a Alexandre; Contra Mídias; Demóstenes; retórica antiga; prática oratória. 